\title{
The ecology of chronic wasting disease in wildlife
}

Luis E. Escobar ${ }^{1, *, \dagger}$, Sandra Pritzkow ${ }^{2, \dagger}$, Steven N. Winter ${ }^{1} \oplus$, Daniel A. Grear
Megan S. Kirchgessner A. Townsend Peterson ${ }^{7, \dagger}$ and Claudio Soto $2, \uparrow$

${ }^{1}$ Department of Fish and Wildlife Conservation, Virginia Tech, Blacksburg, VA, 24061, U.S.A

${ }^{2}$ Mitchell Center for Alzheimer's Disease and Related Brain Disorders, Department of Neurology, University of Texas Medical School at Houston, Houston, TX, 77030, U.S.A

${ }^{3}$ US Geological Survey National Wildlife Health Center, Madison, WI, 59711, U.S.A

${ }^{4}$ Virginia Department of Game E Inland Fisheries, Blacksburg, VA, 24060, U.S.A

${ }^{5}$ Wildife Center of Virginia, Waynesboro, VA, 22980, U.S.A

${ }^{6}$ Department of Population Health and Pathobiology, College of Veterinary Medicine, North Carolina State University, Raleigh, NC, 27606, U.S.A

${ }^{7}$ Biodiversity Institute and Department of Ecology and Evolutionary Biology, The University of Kansas, Lawrence, KS, 66045, U.S.A

\begin{abstract}
Prions are misfolded infectious proteins responsible for a group of fatal neurodegenerative diseases termed transmissible spongiform encephalopathy or prion diseases. Chronic Wasting Disease (CWD) is the prion disease with the highest spillover potential, affecting at least seven Cervidae (deer) species. The zoonotic potential of CWD is inconclusive and cannot be ruled out. A risk of infection for other domestic and wildlife species is also plausible. Here, we review the current status of the knowledge with respect to CWD ecology in wildlife. Our current understanding of the geographic distribution of CWD lacks spatial and temporal detail, does not consider the biogeography of infectious diseases, and is largely biased by sampling based on hunters' cooperation and funding available for each region. Limitations of the methods used for data collection suggest that the extent and prevalence of CWD in wildlife is underestimated. If the zoonotic potential of CWD is confirmed in the short term, as suggested by recent results obtained in experimental animal models, there will be limited accurate epidemiological data to inform public health. Research gaps in CWD prion ecology include the need to identify specific biological characteristics of potential CWD reservoir species that better explain susceptibility to spillover, landscape and climate configurations that are suitable for CWD transmission, and the magnitude of sampling bias in our current understanding of CWD distribution and risk. Addressing these research gaps will help anticipate novel areas and species where CWD spillover is expected, which will inform control strategies. From an ecological perspective, control strategies could include assessing restoration of natural predators of CWD reservoirs, ultrasensitive CWD detection in biotic and abiotic reservoirs, and deer density and landscape modification to reduce CWD spread and prevalence.
\end{abstract}

Key words: Cervidae, Chronic Wasting Disease, CWD, prions, reservoirs, spread, wildlife, zoonotic.

\section{CONTENTS}

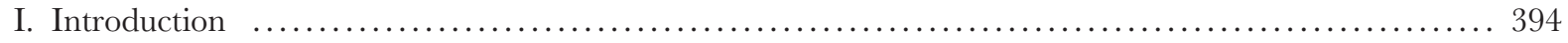

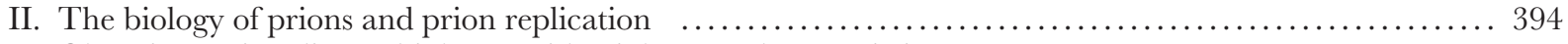

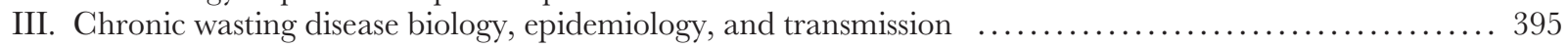

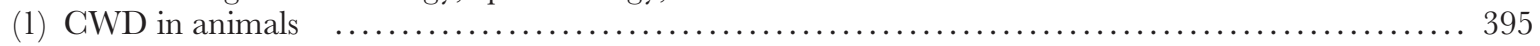

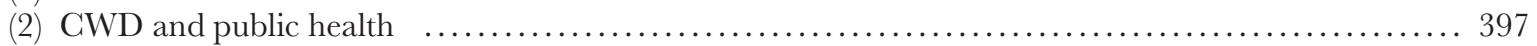

* Author for correspondence (Tel: +1(540) 232-8454; Email: escobar1@vt.edu)

${ }^{\dagger}$ Authors contributed equally. 


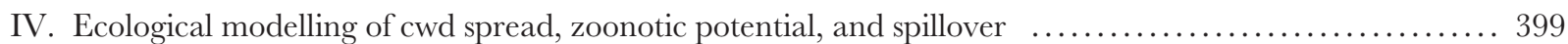

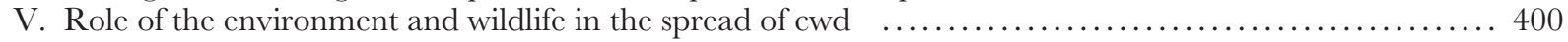

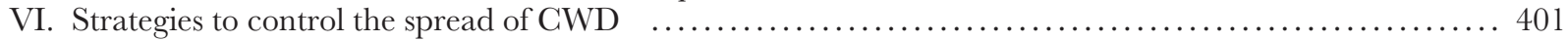

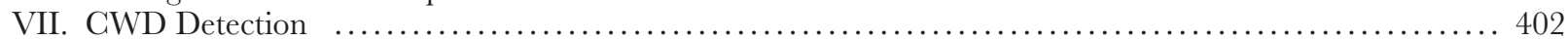

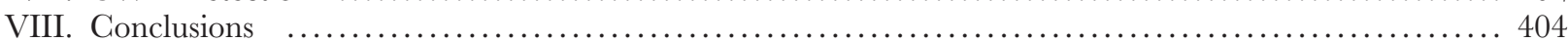

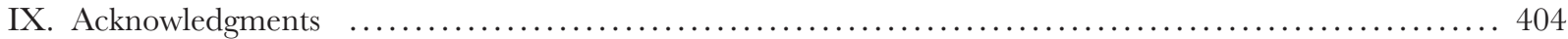

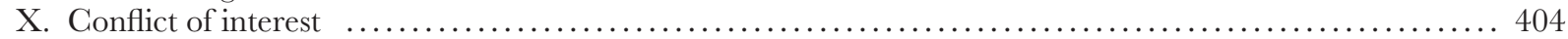

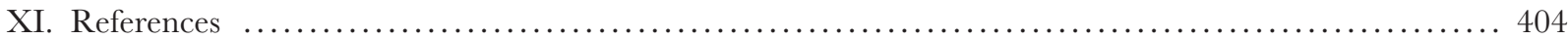

\section{INTRODUGTION}

Prions (see Table 1) are the proteinaceous infectious agents responsible for human and animal prion diseases (Prusiner, 1982). Prions are composed of a misfolded aggregated form of the prion protein (termed $\mathrm{PrP}^{\mathrm{Sc}}$ ) that is able to template the conversion of the natively folded prion protein $\left(\mathrm{PrP}^{\mathrm{C}}\right)$ through a seeding mechanism resulting in the formation of large amyloid-like fibrillar aggregates that accumulate in the brain of infected hosts (Prusiner, 1982; Soto, 2012). The chain reaction of prion replication leads to the accumulation of toxic structures, resulting in progressive neurodegeneration, and is invariably fatal to the host (Prusiner, 1982). Five prion diseases are currently recognized in humans (Creutzfeldt-Jakob Disease, Variant Creutzfeldt-Jakob Disease, Gerstmann-Straussler-Scheinker Syndrome, Fatal Familial Insomnia, and Kuru) and seven in animals (Bovine Spongiform Encephalopathy, Ungulate Spongiform Encephalopathy, Scrapie, Transmissible mink Encephalopathy, Camel Prion Disease, Feline Spongiform Encephalopathy, and Chronic Wasting Disease, or CWD) (Johnson, 2005; Babelhadj et al., 2018; CDC, 2018b).

\section{THE BIOLOGY OF PRIONS AND PRION REPLICATION}

The main event in prion disease is the conversion of the natively folded $\operatorname{Pr} \mathrm{P}^{\mathrm{C}}$ into the misfolded, toxic, and infectious $\mathrm{PrP}^{\mathrm{Sc}}$, which generates a neurodegenerative disease expressed histopathologically as spongiform encephalopathy (Soto \& Satani, 2011). However, the molecular basis of these disorders and the factors that trigger the protein misfolding and initiate the pathology remain unclear (Prusiner, 1998). In humans, genetic forms of prion disease are linked to mutations in the gene encoding for the prion protein (Prmp), which likely induce the misfolding and aggregation process, increasing rates of prion replication. On the other hand, acquired forms of prion diseases in humans and animals are caused by exposure to infectious $\operatorname{PrP}^{\mathrm{Sc}}$ (e.g. iatrogenic infection).

In humans, the most prevalent form of the disease has a sporadic origin, i.e. unknown etiology. Various hypotheses have been proposed to explain the formation of the first prion molecules in sporadic prion diseases (Safar, 2012). One possibility is that somatic mutations or errors in protein synthesis may initiate the chain reaction of protein misfolding. Other possibilities are stochastic changes to the structure of $\operatorname{Pr}^{\mathrm{C}}$ or a failure in the biological clearance of misfolded proteins to eliminate low levels of $\mathrm{PrP}^{\mathrm{Sc}}$ produced continuously during life. Fluctuations in the environment (e.g. changes in $\mathrm{pH}$, salinity, temperature) could influence the persistence of infectious prions in the landscape (Bartelt-Hunt \& Bartz, 2013), so these changes may also enhance spontaneous protein misfolding and prion replication, but this possibility has not been explored. Another hypothesis suggests that prion formation might be promoted or accelerated by traumatic brain injury, which potentially damages tissues and/or axons facilitating metabolic, ionic, and cytoskeletal damage, or causes transcriptional errors that trigger improper folding and clumping of proteins inside nerve cells in the brain (e.g. neurons or astrocytes), as observed for tau protein (Woerman et al., 2016; Rubenstein et al., 2017; Edwards et al., 2019).

In wildlife, chronic trauma could come from agonistic behaviour of males from the families Cervidae (deer) and Bovidae (cattle and sheep) during dominance displays, in which heads are used as weapons during fighting (i.e. 'rutting'; Barrette, 1977). Chronic trauma behaviour is exhausting, damaging, and potentially lethal (Wilkinson \& Shank, 1976; Barrette, 1977; Leslie \& Jenkins, 1985; Geist, 1986; de Vos, Brokx \& Geist, 2016). Chronic trauma has not been studied in the context of CWD in animals. However, this phenomenon could mirror the effects of traumatic brain injury in human neurodegenerative diseases, such as chronic traumatic encephalopathy produced by the accumulation of misfolded aggregates composed of the tau protein (Woerman et al., 2016; Rubenstein et al., 2017; Edwards et al., 2019). Thus, chronic trauma may have played a role in the origin of CWD and in recent 'spontaneous' CWD reports in Scandinavia (Benestad et al., 2016; Evira, 2018; Vikøren et al., 2019), although this remains speculative and further research is required.

An important characteristic of the prion agent is its ability to infect some species and not others. This phenomenon is known as the species barrier (Hill \& Collinge, 2004; Moore, Vorberg \& Priola, 2005). The species barrier in prion disease is mostly controlled by similarity in the $\operatorname{PrP}$ sequence between the donor and receptor species, but it is also known to be dependent on the strain features of the infectious material, which are dependent on structural differences in infectious $\mathrm{Pr}^{\mathrm{Sc}}$ (Hill \& Collinge, 2004; Moore et al., 2005). Even between phylogenetically close species 
Table 1. Glossary of terms

\begin{tabular}{|c|c|}
\hline Term & Definition \\
\hline Amyloid & $\begin{array}{l}\text { Protein aggregates with a characteristic intermolecular } \beta \text {-sheet-rich structure which can be stained with } \\
\text { specific dyes, such as Congo red and Thioflavin S. }\end{array}$ \\
\hline $\begin{array}{l}\text { Bovine Spongiform } \\
\text { Encephalopathy }\end{array}$ & $\begin{array}{l}\text { BSE, commonly known as 'mad cow disease', is a prion disease of cattle. BSE is believed to have originated } \\
\text { from scrapie, a prion disease of sheep. BSE generates variant Creutzfeldt-Jakob disease in humans } \\
\text { exposed to infected beef. }\end{array}$ \\
\hline Culling & Killing of targeted animals to reduce disease spread. \\
\hline CWD & $\begin{array}{l}\text { Chronic Wasting Disease is an infectious spongiform encephalopathy known to affect cervids, including } \\
\text { mule deer, white-tailed deer, elk (or 'wapiti'), moose, and caribou. }\end{array}$ \\
\hline ELISA & $\begin{array}{l}\text { Enzyme-linked immunosorbent assay is a biochemical method used to detect antigens based on the use of } \\
\text { specific antibodies to detect the presence of a target protein. }\end{array}$ \\
\hline Feedgrounds & $\begin{array}{l}\text { Artificial food subsidy generally used in wildlife management to sustain wild populations in periods of low } \\
\text { natural food availability (e.g. supplementation of elk in Wyoming with square bales of grass or alfalfa } \\
\text { during the winter). }\end{array}$ \\
\hline Fibrils & Chains of protein aggregates adopting an amyloid structure generally associated with diseases. \\
\hline Large carnivores & Large-sized predators such as mountain lion, bears, and wolves that have broad home ranges. \\
\hline Mesocarnivore & $\begin{array}{l}\text { Mid-sized predators such as a coyote, lynx, and raccoon that consume plants and fungi in addition to meat } \\
(\sim 50 \% \text { prey). }\end{array}$ \\
\hline PMCA & $\begin{array}{l}\text { Protein misfolding cyclic amplification is a diagnostic method based on reproducing the prion replication } \\
\text { process in the laboratory in an accelerated manner through cycles of polymerization/fragmentation to } \\
\text { multiply misfolded prions. A certain set of PMCA conditions is often referred as RT-QuIC. }\end{array}$ \\
\hline Prions & $\begin{array}{l}\text { Term coined by Stanley B. Prusiner after merging the words proteinacious infectious agents. It was } \\
\text { originally used to denote the infectious agent responsible for prion diseases but recently has been used as } \\
\text { a more general term to refer to any misfolded protein that can spread by seeding the conversion of } \\
\text { normal proteins. }\end{array}$ \\
\hline PrP & General abbreviation for prion protein. \\
\hline $\mathrm{PrP}^{\mathrm{C}}$ & Normal PrP found in a healthy host. \\
\hline $\mathrm{PrP}^{\mathrm{Sc}}$ & $\begin{array}{l}\text { Infectious prion causing the spongiform encephalopathy scrapie in sheep, also used to denote the misfolded } \\
\text { and infectious prion protein in general. }\end{array}$ \\
\hline Scrapie & Neurodegenerative disease of sheep and goats caused by the infectious prion $\mathrm{PrP}^{\mathrm{Sc}}$. \\
\hline Spillover & Transmission of a pathogen between two different species. \\
\hline $\begin{array}{l}\text { Variant Creutzfeldt-Jakob } \\
\text { Disease }\end{array}$ & Spongiform encephalopathy of humans caused by exposure to BSE. \\
\hline
\end{tabular}

where the PrP sequence difference is rather small, the species barrier is manifested as a prolongation of the time it takes for animals to develop the clinical disease when inoculated with another species' infectious material (Robinson et al., 2012). Transmission of prion disease has been shown between animals and humans, with a notorious outbreak caused by the transmission of Bovine Spongiform Encephalopathy (BSE) to produce variant Creutzfeldt-Jakob Disease in humans (Ironside et al., 1996).

\section{GHRONIC WASTING DISEASE BIOLOGY, EPIDEMIOLOGY, AND TRANSMISSION}

\section{(1) GWD in animals}

Chronic Wasting Disease (GWD) is the most worrisome member of the group of prion diseases, because it affects wildlife, and is currently spreading rapidly in North America and has recently been detected in Europe (Fig. 1). However, our knowledge of the origins of CWD is limited. The first observation of CWD occurred in 1967 in a captive deer facility in Colorado (Williams \& Young, 1980). There is speculation that CWD emerged in this facility due to scrapie spillover from sheep co-housed there (Blumhardt, 2018). However this has not been confirmed. Instead, this early detection could be related to intense observation by veterinarians in this research facility. More historical-epidemiology research is necessary regarding CWD in Colorado to understand better the apparently spontaneous CWD cases recently confirmed in Europe (Benestad et al., 2016; Evira, 2018; Vikøren et al., 2019).

Experimental challenges using infected brain homogenate of scrapie-infected sheep suggest that scrapie prions from sheep can infect elk (Cervus elaphus nelsoni) (Hamir et al., 2004) and white-tailed deer (Odocoileus virginianus) (Greenlee, Smith \& Kunkle, 2011). However, to date, scrapie transmission to cervids has only been documented generally using infectious routes that are not epidemiologically relevant (e.g. intra-cranial inoculation). CWD was the first, and continues to be the clearest, example of a transmissible prion among free-ranging wildlife. Experiments and observations demonstrate that CWD prion transmission can occur vertically (e.g. mother to offspring) (Selariu et al., 2015) or horizontally (e.g. direct animal contact, environmental 


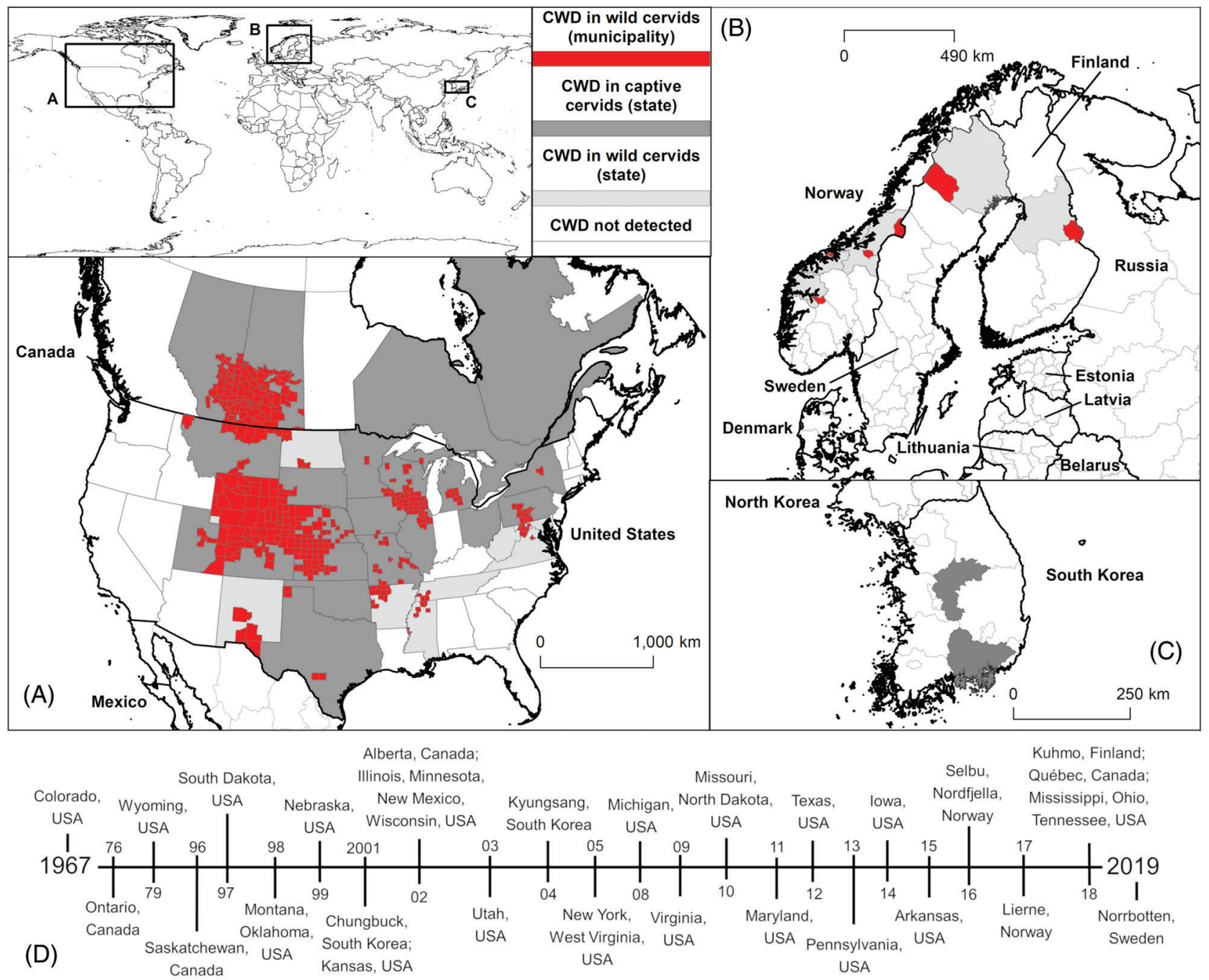

Fig. 1. Geographic distribution of Chronic Wasting Disease (CWD) reports. (A) The region with the most cases and areas infected with CWD is North America; (B) Europe has reported GWD in Norway, Sweden, and Finland; (C) Asia reported GWD in South Korea. Red: counties (in USA) and wildlife management areas (in Canada) with reports of CWD in wild cervids; dark grey: states/provinces reporting CWD in captive cervids; light grey: states with CWD detection in wild cervids; white: areas with no reports of CWD; (D) Timeline denoting the first detections of CWD in specified regions for each country. Data derived from CDC (2019) and CWD Alliance (2019).

infection) (Mathiason et al., 2009; Denkers et al., 2013; Zabel \& Ortega, 2017) (Fig. 2). In North America, species known to be susceptible to natural infection include elk, white-tailed deer, mule deer (Odocoileus hemionus), black-tailed deer $(O . h$. columbianus), and moose (Alces alces), and the introduced red deer (C. elaphus) (Williams \& Young, 1980; Spraker et al., 1997; Baeten et al., 2007) (Fig. 3). Europe has documented transmission in free-ranging reindeer (also known as caribou; Rangifer tarandus), red deer, and moose in Norway, Sweden, and Finland (Benestad et al., 2016; Evira, 2018; Vikøren et al., 2019). South Korea has reported CWD in captive elk transferred from a Canadian captive cervid facility (Kim et al., 2005). After infection, incubation period in wild cervids is generally between 2 and 4 years with a minimum of 16 months before development of symptoms (Williams, 2005).
During the pre-clinical, asymptomatic phase, prions can be detected in faeces, urine, and saliva as early as 6 months post-infection (Plummer et al., 2017). Symptoms associated with late-stage CWD infection include emaciation, excessive salivation, behavioural changes, ataxia, depression, and weakness (Williams \& Young, 1980; Spraker et al., 1997).

The USA has the most widespread CWD infection in the world (Fig. 1). As of August 2019, the USA had confirmed GWD in 26 states, including in free-ranging cervids in 279 counties in 24 states (CDG, 2019) and in captive deer in 17 states (USGS, 2019). In some of these localities, CWD prevalence in wild white-tailed deer reached as high as $40 \%$ in adult females and $50 \%$ in adult males (Edmunds et al., 2016; Carlson et al., 2018). The highest infection rate has usually been found in older males followed by 


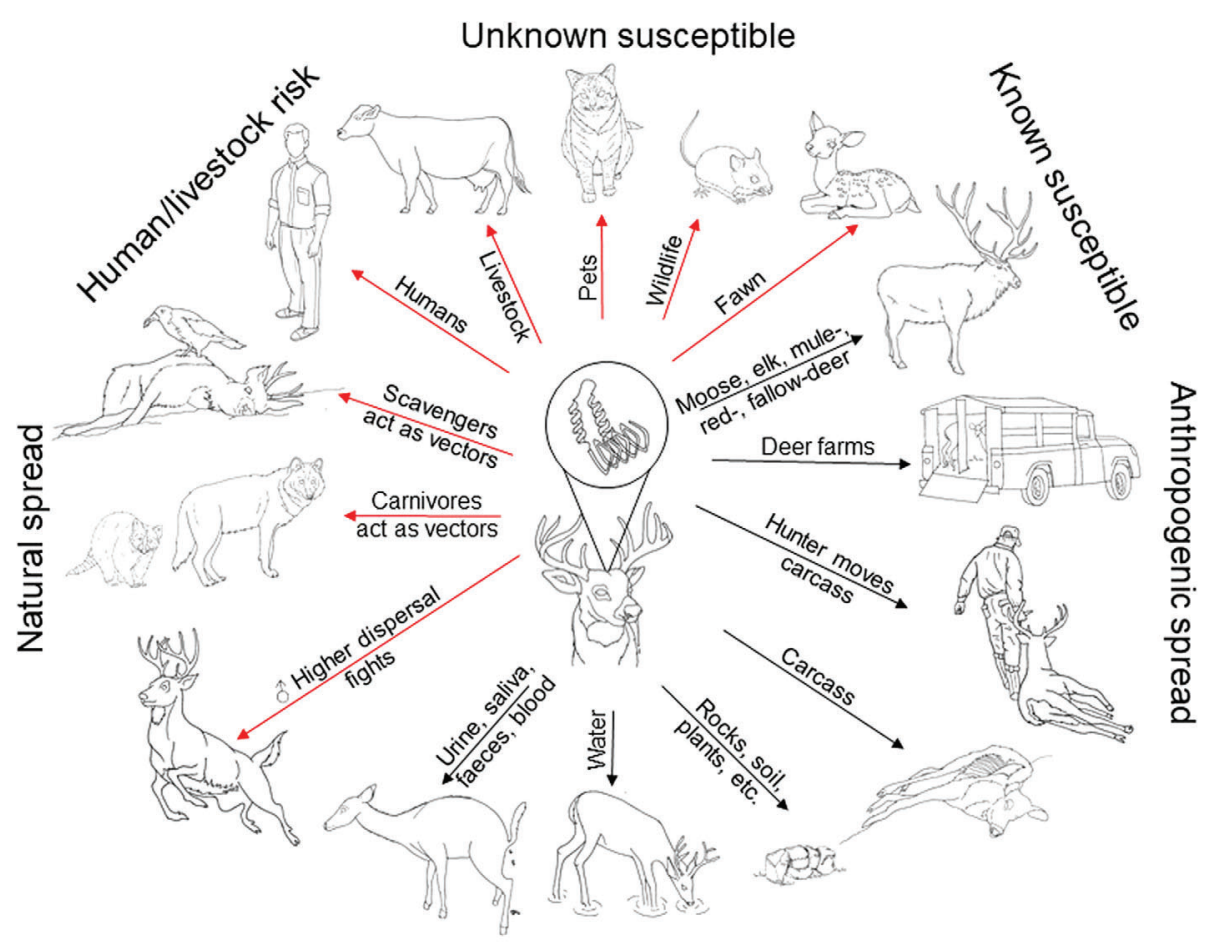

Environmental reservoirs

Fig. 2. Role for intermediate species and environmental reservoirs in the spread of Chronic Wasting Disease (CWD). Wild cervid populations serve as the reservoirs of CWD (Carlson et al., 2018), acting as source for spillover to other species and the environment. Natural spread: spread in natural areas associated with high CWD prevalence and dispersal observed in male white-tailed deer (Clements et al., 2011; Carlson et al., 2018). Unknown susceptible: species that have shown successful PrP ${ }^{\mathrm{Sc}}$ infection under experimental settings, but for which no evidence is available under natural conditions; potentially susceptible predators (e.g. coyotes) and scavengers (e.g. crows and raccoons) exist that could act as vectors of the infectious prion (Bunk, 2004; Hamir et al., 2007; Fischer et al., 2013; Moore et al., 2019). Similarly, while fawns are known to be susceptible, little is known of their role in the shedding and spread of CWD. Known susceptible: species known to be susceptible to CWD infection, including mule deer, black-tailed deer, elk, white-tailed deer, red deer, moose, and reindeer (caribou) (Williams \& Young, 1980; Spraker et al., 1997; Baeten et al., 2007; Benestad et al., 2016; Evira, 2018). Species susceptible in laboratory experiments include Reeve's muntjac and fallow deer. Anthropogenic spread: spread of CWD facilitated by human intervention, including translocation of infected deer (e.g. deer farms, carcasses of infected deer). Environmental reservoirs: infected fluids or tissues (e.g. urine, saliva, faeces, blood) deposited in the environment (e.g. water, grass, soil, rocks) remaining infectious for months, years, or decades. Black arrows, observed in the wild or in laboratory conditions; red arrows, uncertain, requiring additional research.

older females, and yearling males (Heisey et al., 2010), but not in all areas (Edmunds et al., 2016). Older males may be at the highest risk due to their broader home range, which increases their chance of interacting with infected deer or contaminated landscapes, their less-cohesive social structuring than in females, and their higher contact during the mating season (e.g. fights with other males, allogrooming courtship, copulation, scent verification). In North American elk and deer species, males disperse (permanent movement away from a natal range) more frequently than females (Skuldt, Mathews \& Oyer, 2008; Clements et al., 2011; Miller \& Conner, 2013; Nobert et al., 2016) (Fig. 2). However, other movement behaviours such as migration (primarily in western North America) (Conner \& Miller, 2004; Farnsworth et al., 2006) and exploratory movements of young individuals (Oyer, Mathews \& Skuldt, 2007) also potentially impact the spatial spread of prions without being linked to dispersal behaviours. Indeed, CWD infection itself could impact prion spread: CWD causes increased activity (hyperexcitability) in the early stages of infection and a search for drinking water in the late clinical stages (e.g. insipidus-like syndrome of polydipsia) (Williams \& Young, 1993; Miller, Wild \& Williams, 1998). Additionally, infected deer reduce their spatial movements late in infection due to the diminished alertness, movement, and lethargy observed in the clinical phase of the disease (Fox et al., 2006; Edmunds et al., 2018). Reduced spatial movement during the last stage of the infection may facilitate concentration of infectious material in specific locations.

\section{(2) GWD and public health}

The potential for CWD to infect humans is highly controversial, but the general consensus is that transmission to humans cannot be entirely ruled out based on current 


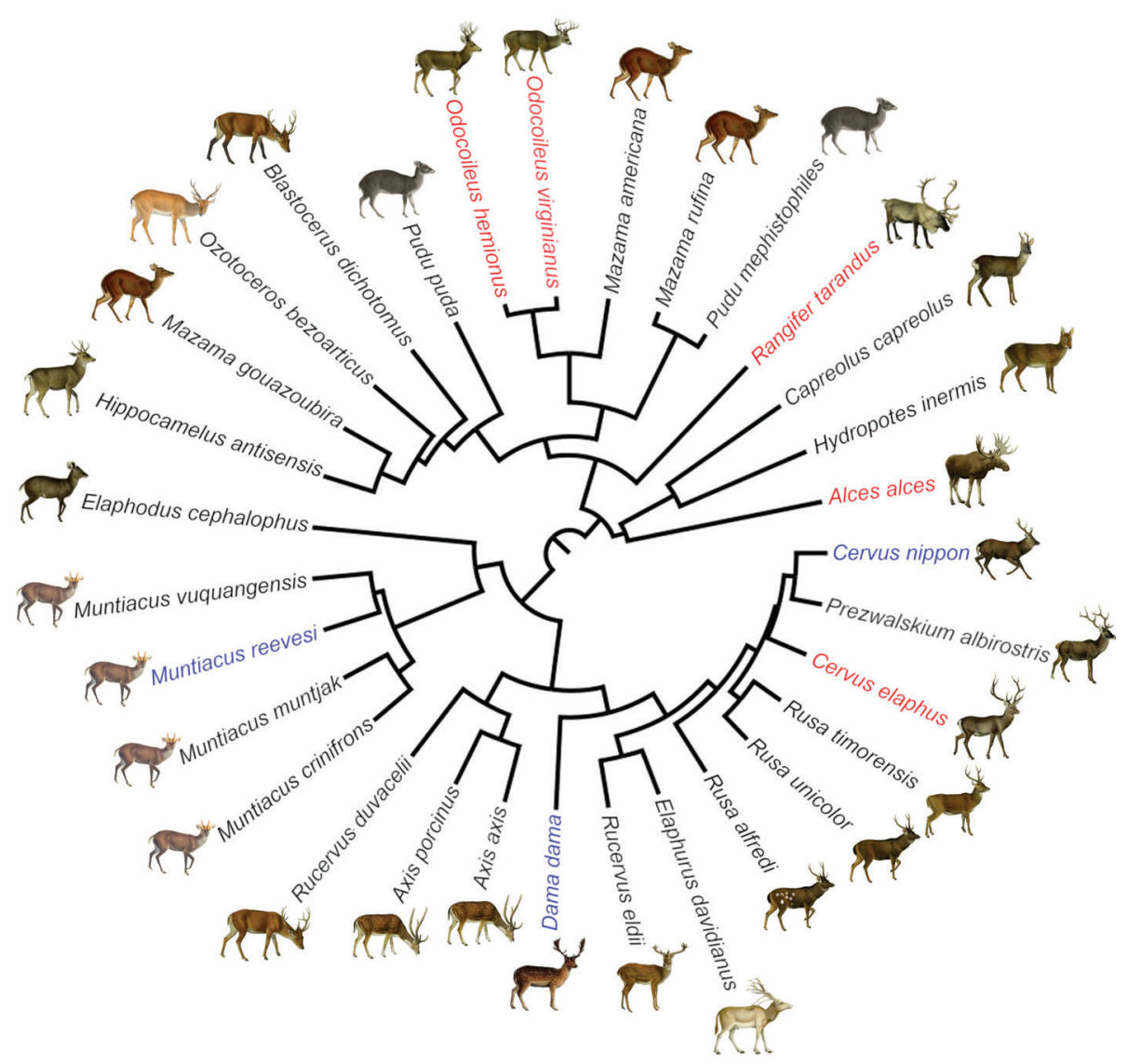

Fig. 3. Taxonomic breadth of Chronic Wasting Disease (CWD) infections in the Cervidae. Cladogram denotes cervid species found naturally susceptible (red), susceptible under experimental inoculation (blue), and of unknown susceptibility (black). Figure modified from Gilbert et al. (2006), based on species classification from the Integrated Taxonomic Information System (www.itis.gov) and sequences available from Genbank (https://www.ncbi.nlm.nih.gov/genbank/). Deer illustrations from Lydekker (1898).

evidence (Waddell et al., 2018). Experiments using transgenic mouse models have shown negative results for zoonotic risk (Kong et al., 2005; Tamguney et al., 2006; Sandberg et al., 2010). Using in vitro conversion studies, it was found that CWD prions can replicate at the expense of the human protein, but only after the CWD strain has been adapted by various rounds of replication in deer (Barria et al., 2011), suggesting that under certain conditions CWD may threaten human health. Notably, CWD was shown to transmit to various species of non-human primates (Marsh et al., 2005). Of particular note, recent studies report transmission of CWD to macaques (Macaca fascicularis) even by oral administration of brain and muscle tissues (Czub et al., 2017) but these results have been questioned (Race et al., 2018). The USA Centers for Disease Control and Prevention (CDC) recommend that people who harvest deer from CWD-affected areas test their deer or elk for CWD and do not consume venison from a known CWD-positive cervid (CDC, 2018a).

A recent in vitro assessment showed that CWD zoonotic potential is affected by factors such as $\mathrm{PrPSc}^{\mathrm{Sc}}$ strain, cervid species, and geographical location from which CWD originates. In one study, $\mathrm{PrP}^{\mathrm{Sc}}$ from white-tailed deer did not show zoonotic potential, while $\mathrm{PrP}^{\mathrm{Sc}}$ from elk and reindeer were compatible with the human protein (Barria et al., 2018), supporting the idea of strain-specific risk for human CWD infection that has yet to be considered in zoonotic risk assessments. Transmission of CWD from wildlife to cattle has been observed only under experimental conditions (Hamir et al., 2001, 2005). Neither livestock nor humans have developed the disease, even after residing in CWD-endemic areas for decades. A renewed concern is that the CWD situation mirrors the early stages of BSE research, in which a limited number of species was thought to be susceptible to infection (e.g. mice, hamsters, and primates) (Osterholm et al., 2019). At that time, it was thought that scrapie-associated prions causing BSE would not infect people based on the fact that people ate scrapie-infected meat for centuries with no evidence of infection (Bunk, 2004). It was discovered later that BSE is able to cross the species barrier and infect humans after oral exposure (Johnson, 2005). Changes in prion composition and virulence occur during passages through different species (Raymond et al., 2007; Race et al., 2018), suggesting that the crossing of the species barrier in humans may not emerge directly from the most frequent reservoir (i.e. white-tailed deer), as occurred with BSE (Bunk, 2004). For example, 
CWD from cervids has showed amplified virulence and adaptation after spillover to rodents (Raymond et al., 2007), including rodent species overlapping with CWD-infected cervids in the wild (Heisey et al., 2010). Thus, even when the CDC states that 'If CWD could spread to people, it would most likely be through eating of infected deer and elk' (CDC, 2018a, https://www.cdc.gov/prions/cwd/ prevention.html), disease ecology theory suggest that full assessments of zoonotic CWD risk should consider spillover from other species.

\section{EGOLOGIGAL MODELLING OF GWD SPREAD, ZOONOTIC POTENTIAL, AND SPILLOVER}

Infectious diseases are not distributed randomly across landscapes (Peterson, 2014; Escobar \& Craft, 2016). Models accounting for landscape or climate configuration to quantify environmental conditions where spread of diseases occurs are used to understand distributional disequilibrium in the spread of diseases (Benavides, Valderrama \& Streicker, 2016; Hutter et al., 2016; Piaggio et al., 2017), like CWD, that are undergoing range expansions. Interestingly, the available studies conducted at landscape levels also suggest that CWD does not occur randomly across taxonomic, temporal, geographic, and environmental spaces (Mathiason et al., 2009) (Fig. 4).

CWD was first linked to captive deer in Colorado (Fig. 1) (Williams \& Young, 1980), but its subsequent spread has remained a mystery. Some detections have been linked to the translocation of infected captive cervids to previously uninfected cervid farms (Joly et al., 2003), including the spread of CWD in the USA and Canada (Evans, Schuler \& Walter, 2014) and between Canada and Asia (Lee et al., 2013). For example, the transfer of infected captive cervids from the USA to Canada resulted in the spread of the CWD to at least one facility in Ontario and a captive cervid farm in Saskatchewan (Bollinger et al., 2004). Some detections of CWD in free-ranging cervids were preceded by detection in proximate captive herds, but this has not been consistent over the 40+ years of CWD spread (Olszowy et al., 2014; Haley \& Hoover, 2015). In North America, over 175 captive cervid facilities have diagnosed CWD on their premises, with up to $80 \%$ of the herd infected in some cases (Carlson et al., 2018) (Fig. 2).

Spread of CWD in captive cervids suggests that transmission may be more effective in high-density herds and that facilities may act as effective point sources for infection (Bartelt-Hunt \& Bartz, 2013; Zabel \& Ortega, 2017). In North America, the spatial distribution of infected deer farms seems to follow a latent spatial process that appears clustered (Fig. 1). Similar patterns are observed in modelling wild populations (Joly et al., 2006), as disease prevalence typically declines with distance from heavily affected areas and landscape connectivity plays a larger role in the spread of disease (Conner \& Miller, 2004; Joly et al., 2006;

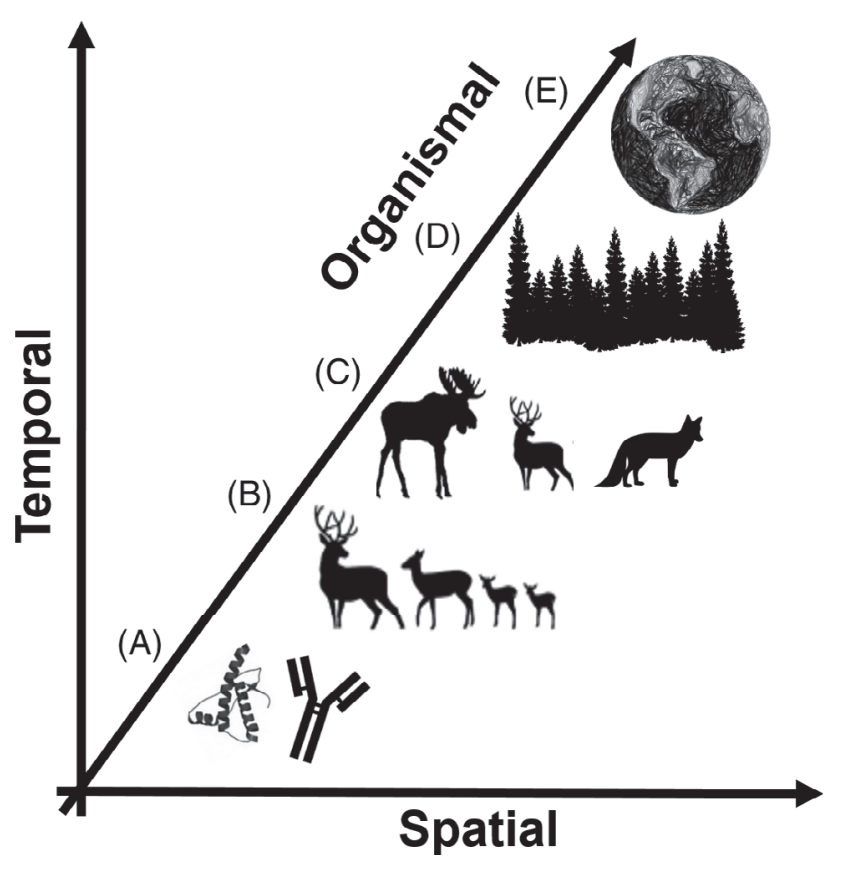

Fig. 4. Different dimensions and scales (micro to macro) to study Chronic Wasting Disease (CWD). Three dimensions could be used to study CWD: spatial, temporal, and organizational dimensions. The $x$ axis denotes the spatial dimension (from millimetres to continents); the $y$ axis denotes the temporal dimension (from seconds to centuries); the $z$ axis denotes the organizational dimension (from molecules to biomes). Micro: (A) molecular-level studies focus on prion detection and characterization, e.g. in vitro measurements on prion conversion; (B) population-level studies explore transmission between individuals of a group, e.g. transmission experiments in captive deer; and $(\mathbf{C})$ community-level studies explore potential CWD spillover among species, e.g. evaluating the role of other wild species in prion dissemination and maintenance. Medium: (D) landscape-level studies aim to identify biotic and abiotic factors associated with CWD maintenance and spread in endemic areas, e.g. assessing CWD distribution based on landscape configuration among seasons. Macro: (E) biogeographic-level studies aim to understand factors associated with CWD spread among large regions, periods, and communities, e.g. exploring climatic drivers of CWD occurrence at a continental level or long-distance spread from translocation of captive cervids. The different organizational levels can be studied across different geographic and temporal scales (e.g. from fine to coarse). Most CWD research has been restricted to studies at low organization level and fine temporal and spatial scales. Studies at the community, landscape, and biogeographic levels underlying CWD occurrence remain neglected and are critically needed.

Blanchong et al., 2008; Nobert et al., 2016). It is evident that CWD does not occur randomly in the geography, and geomorphology seems to play a role shaping its distribution (Fig. 5). However, coarse-scale biogeographic assessments of CWD distribution have not yet been performed. Similarly, the role of sampling bias in the structure of disease spread has not been studied in detail.

Sampling bias may limit our understanding of current CWD distribution (Conner, McCarty \& Miller, 2000), with 


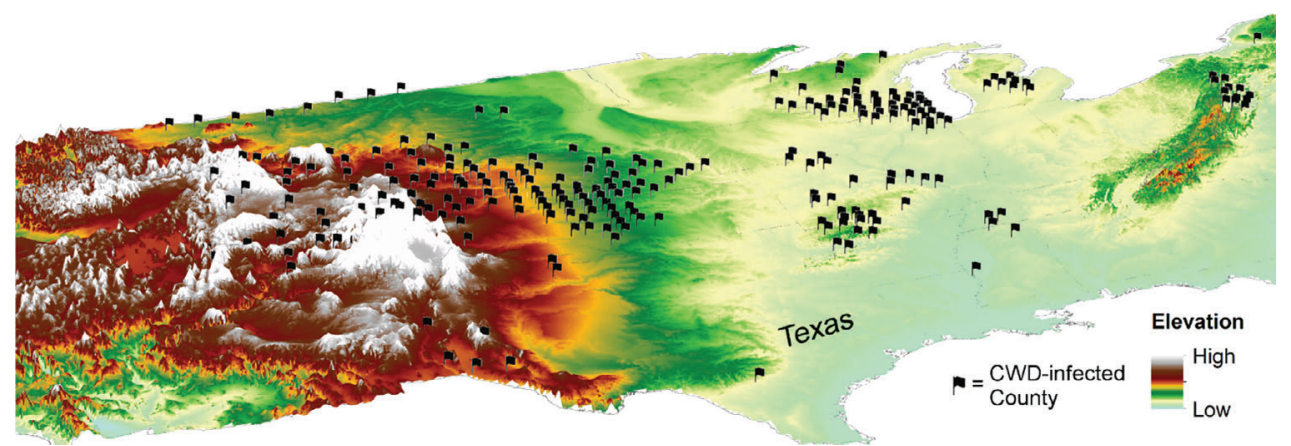

Fig. 5. Geomorphology and Chronic Wasting Disease (CWD). USA counties reported as CWD-positive in wildlife (black flags). Note the geomorphology of the country with areas of low (blue) and high elevation (white). The map suggests that CWD is broadly found in flat landscapes with plausible interruption or retardation of spread in the highlands of western (e.g. Utah, Idaho, western Colorado) and eastern regions (e.g. Appalachian Mountains).

the bulk of samples provided by hunters - i.e. current patterns of CWD distribution are influenced by sampling effort. A potential strategy to mitigate sampling bias would require rigorous analyses of environmental drivers underlying CWD dynamics in wildlife at different spatial and temporal scales (Plowright et al., 2008). Novel applications of multiscale modelling methods and theory from ecology and biogeography have facilitated identification of factors related to transmission, spread, and establishment of infectious diseases across large areas and a large number of species (Estrada-Peña et al., 2014; Peterson, 2014; Gortázar et al., 2014), but such approaches have never been applied to prion diseases, with most prion research conducted at population level (Fig. 4).

Beyond elk, deer (red, mule, white-tailed, black-tailed), and moose populations, the role of other species in CWD maintenance has not been explored extensively. Experimental data, generally using intra-cranial inoculation (Hamir et al., 2008), reveal that rodents (voles, mice, hamsters) (Bartz et al., 1998; Raymond et al., 2007; Heisey et al., 2010; Watts et al., 2014; Orrú et al., 2015), mesocarnivores (ferrets, mink, cats) (Bartz et al., 1998; Sigurdson et al., 2008; Perrott et al., 2013), livestock (cattle, sheep, pigs) (Hamir et al., 2001, 2005, 2006, 2007; Madsen-Bouterse et al., 2016; Moore et al., 2017), and other deer species (Reeve's muntjac, Muntiacus reevesi and fallow deer, Dama dama) (Hamir et al., 2011; Nalls et al., 2013) are susceptible to infectious CWD prions. In vitro and in vivo models have produced mixed results regarding the ability of CWD to cross the species barrier into humans and livestock. To date, CWD remains restricted to cervids (Carlson et al., 2018), however, experimental work has identified a non-negligible spillover potential of CWD into humans or livestock (Mathiason et al., 2006; Haley et al., 2011). Uncertainty in the zoonotic potential of CWD, the magnitude of exposure of non-cervids to CWD, and a lack of tools to prevent CWD spread suggests that CWD is the prion disease with highest epidemiological risk (Jakob-Hoff et al., 2014).

To date, cervids are the only wildlife species monitored epidemiologically in routine CWD surveillance. Specific traits can help to evaluate the roles of other wildlife species as potential disease reservoirs (Luis et al., 2015). Recent studies showed that diverse ecological and evolutionary features describing intrinsic organismal characteristics can be combined to predict species suitable for disease transmission (Olival et al., 2017). For example, based on traits of species, recent studies used supervised machine learning algorithms to identify and prioritize rodent reservoirs of zoonotic diseases (Han et al., 2015), bat species hosting filoviruses (Han et al., 2016), mosquito vectors of Zika virus (Evans et al., 2017), and suitable tick vectors from the genus Ixodes (Yang \& Han, 2018). Future research should explore species traits (e.g. phylogeny, physiology, behaviour) as predictors of associations between features of potential reservoir species, which will help to identify species that can be used in future experimental research, as sentinels for surveillance, and as animal models (Bancroft et al., 2011) (Fig. 2).

\section{ROLE OF THE ENVIRONMENT AND WILDLIFE IN THE SPREAD OF GWD}

Experimental studies have shown that infectious prions can enter the environment through saliva, faeces, urine, blood, antler velvet, or placenta tissue from infected animals, and carcasses (Angers et al., 2009; Zabel \& Ortega, 2017). Importantly, CWD contamination of the environment via prion shedding in cervid excreta occurs many months before the onset of clinical disease (Mathiason et al., 2009; Plummer et al., 2017). Prions are hardy in the environment, are resistant to most general disinfectants (e.g. heating, most disinfectant chemicals, ultraviolet and ionizing radiation), and can remain infective for years to decades (Georgsson, Sigurdarson \& Brown, 2006; Seidel et al., 2007; Smith, Booth \& Pedersen, 2011). We recently reported that plants efficiently bind, uptake, retain, and transport infectious prions (Pritzkow et al., 2015). Other natural or man-made components of the environment, such as soil, rocks, wood, metals, and plastic, bind prions and do not diminish infectivity to susceptible species (Pritzkow et al., 2018). While oral ingestion 
is the most common route of exposure for prion disease, infectious scrapie prions caused $100 \%$ mortality via airborne transmission in a laboratory challenge of mice (Haybaeck et al., 2011). One report suggested that prions bound to soil are more infective than free prions, so soil may serve both as an environmental reservoir and a facilitator of CWD prion transmission (Johnson et al., 2007). Soils of different texture, mineralogy, and organic content appear to bind differently to prions and show distinct infectivity rates via oral or aerosolized transmission (Johnson et al., 2007). For example, soils with high organic material content (e.g. high concentration of humic acid) appear to degrade CWD prions faster (Kuznetsova et al., 2018).

Direct exposure of non-cervid animals to CWD-infected cervids could help to spread CWD. For example, hawks, owls, crows, dogs, cats, coyotes, raccoons, skunks, mink, foxes, and opossums that consume deer carcasses could act as spillover hosts and potentially vector spreaders of CWD (Bunk, 2004; Jennelle et al., 2009), although there has been no detection of CWD in any of these species (Fig. 2). Additionally, supplemental wildlife feeding can increase disease transmission by exacerbating deer densities, increasing contact rates, altering normal behaviour, and prolonging exposure to potentially contaminated areas (Thompson, Samuel \& Van Deelen, 2008). For example, feeding grounds used to subsidize wild elk during the winter (e.g. in Wyoming) increase the risk of disease transmission (Creech et al., 2012). Similarly, recent detection of CWD $\mathrm{PrP}^{\mathrm{Sc}}$ in ecologically relevant environments, such as natural mineral licks where wildlife obtain minerals from soil and water consumption, suggests a key role of landscape features in CWD transmission risk (Plummer et al., 2018). Thus, identifying where and when CWD occurs in a timely fashion can help inform policies regarding baiting and supplemental feeding of cervids and to consider direct habitat modification with the aim of reducing infectious contact (Sorensen, van Beest \& Brook, 2014). Identifying the environmental conditions that facilitate or limit CWD infectivity, as well as the relative importance of CWD transmission from environmental reservoirs versus direct animal-animal transmission, may help to identify potential control methods (Grear et al., 2010).

\section{STRATEGIES TO GONTROL THE SPREAD OF GWD}

Expanding CWD research from fine-scale to landscape- and biogeographic-level studies will enhance our understanding of its occurrence across species, areas, and time periods (Levin, 1992). Available epidemiological data can be used to determine CWD prevalence, identify locations for surveillance, calculate sampling effort required to inform early warning systems, and guide hunting or culling to reduce CWD transmission (Rees et al., 2012). Epidemiological data can identify the location, species, and diagnostic method most effective for CWD surveillance and early detection, and to identify areas where citizen education and extension are crucial (Sorensen et al., 2014). International efforts are necessary for the development of standardized and systematic surveillance efforts in wildlife as an early warning system to anticipate CWD spread and the emergence of new prion diseases (Johnson, 2005).

Prion protein polymorphisms and strain diversity likely have important effects on the efficiency of prion transmission, so further knowledge of these aspects may contribute to the implementation of strategies for CWD reduction. Some reports have demonstrated the existence of distinct CWD prion strains (Angers et al., 2010; Crowell et al., 2015; Duque-Velásquez et al., 2015; Bian et al., 2019). However, limited tools exist to determine the origins and full diversity of natural prion strains in the wild-captive interface of CWD (Igel-Egalon et al., 2018), limiting our capacity to identify the directions and effects of CWD spillover.

Epidemiological surveillance data coupled with landscape and community ecology analyses can help to determine how changes in the landscape and population configuration impact CWD circulation. For example, focal and consistent culling has been shown to reduce the prevalence of CWD in some wild cervid populations (Manjerovic et al., 2014; Sorensen etal., 2014), and simulations suggest that this approach can even eliminate the disease in certain situations (Potapov, Merrill \& Lewis, 2012). This observation suggests that if CWD is discovered in high-value (endangered or conservation priority) isolated populations, where culling is not feasible, field testing and immediate culling of CWD-positive individuals could be economically and logistically feasible (Wolfe, Miller \& Williams, 2004; Plummer et al., 2018). Combining theoretical approaches with surveillance data shows that deer density has varying levels of influence on contact rates and mechanisms of transmission (Storm et al., 2013; Potapov et al., 2013; Jennelle etal., 2014). Still, despite past debate on the density dependence of CWD transmission, it appears consistent that culling of CWD-positive individuals and landscape heterogeneity affect CWD prevalence at the population level (Conner et al., 2008; Wasserberg et al., 2009; Habib et al., 2011). Population models suggest that CWD generates selective pressures on deer populations and shapes the genetic diversity of populations by selecting for PrP genotypes associated with slower progression to clinical symptoms and death (Robinson et al., 2012). Overall, the frequencies of $\mathrm{PrP}$ genotypes associated with slower time to CWD death are low; importantly, no PrP genotypes are known that are truly resistant to CWD infection (Robinson et al., 2012). This selective process, however, is slow because of the chronic nature of CWD mortality. Williams et al. (2014) modelled the outcomes of a selective process on elk at the scale of decades to 100 years. The role that $\operatorname{PrP}$ genotypes play in shaping the population trajectories of CWD-infected cervid herds will likely be modified by hunting, which generally targets individuals in the oldest age class, of a specific sex (i.e. males may be targeted for trophy management or females targeted for population control), and acts at a time scale an 
order of magnitude faster than PrP genotype selection (i.e. harvest causes non-selective mortality yearly versus selection occurring over decades or longer with regards to CWD genotype).

Considering the capacity of infectious prions to remain infective in specific landscape components (Fig. 2), identifying landscape configurations that facilitate CWD transmission is a high priority for future research. For example, analyses including CWD occurrence and specific vegetation phenologies, soil structure and composition, and local temperature and moisture, will allow researchers to identify landscape-level hotspots of CWD transmission risk to target deer control or landscape management. Thus, disentangling the landscape components that facilitate CWD transmission will expand the tools available to managers to modify such components via prescribed fire, habitat restoration, soil management, etc. to reduce their role as environmental reservoirs of CWD.

Beyond the landscape, other species in the community can influence CWD transmission. Empirical evidence supports the role of predators in the removal of sick and infectious prey across diverse disease systems (Packer et al., 2003). For example, grey wolf (Canis lupus) presence reduced seroprevalence of bovine-virus-diarrhea in elk (Barber-Meyer \& White, 2005), and mountain lions (Puma concolor) selectively predate on CWD-infected mule deer (Krumm et al., 2010). Other native large predators, such as grey wolves and bears (Ursus spp.), may similarly influence the prevalence and geographic distribution of CWD in wild reservoirs, as demonstrated through modelling applications (Hobbs, 2006; Wild et al., 2011). Additionally, numbers and geographic range of predators, including wolves and black bears (Ursus americanus), can be successfully managed and controlled via wildlife management methods (Meagher \& Phillips, 1980; Clark, Huber \& Servheen, 2002; Soorae, 2013).

Research assessing the role of predators in CWD transmission requires a multidisciplinary approach integrating expertise in human dimension, epidemiology, and ecology. Alternatively, carnivores and scavengers could potentially facilitate CWD spread to distant areas by translocating infectious prions from prey. This has been suggested for scats of coyotes (Canis latrans), raccoons (Procyon lotor) (Hamir et al., 2007; Moore et al., 2019), and crows (Corvus spp.) (Fischer et al., 2013), but has not been tested empirically. Scats may also be of potential utility in CWD surveillance and early detection, as predators can selectively predate CWD-infected cervids (Nichols et al., 2015). Whether predators can significantly improve the control and surveillance of CWD is unknown but deserves deeper exploration. Predator or scavenger scats have not been used in CWD surveillance to date.

\section{GWD DETEGTION}

Development of new diagnostic methods for disease detection can change interpretations of past research findings.
In CWD research, methods used for the detection of prion-infected animals include immunohistochemistry (IHC) (Peters et al., 2000), enzyme-linked immunosorbent assay (ELISA) (Hibler et al., 2003), western blotting (WB) (Guiroy et al., 1993), protein misfolding cyclic amplification (PMCA) (Saborio, Permanne \& Soto, 2001), and real-time quaking induced-conversion (RT-QuIC) (Henderson et al., 2015). All these methodologies are based on the detection of infectious $\mathrm{PrP}^{\mathrm{Sc}}$, but they have very different degrees of sensitivity and specificity. This disparity can lead to potentially inaccurate heuristics in detection procedures, and in turn, in our overall comprehension of CWD prevalence, distribution, and natural transmission.

Western Blotting, ELISA, and IHC detect $\mathrm{PrP}^{\mathrm{Sc}}$ directly using specific antibodies. These techniques have been regarded as the 'gold standard' of official post-mortem diagnostic methods (Haley \& Richt, 2017; USDA, 2019). Western Blotting, ELISA, and IHC, however, fail to identify low levels of $\mathrm{PrP}^{\mathrm{Sc}}$, which are likely present in animals recently exposed to GWD. On the other hand, PMCA and RT-QuIC show higher (ultra) sensitivity of detection than IHC, ELISA, or WB methods (Haley et al., 2009; Holcomb, Galloway \& Mathiason, 2016). PMCA and RT-QuIC rely on the amplification of $\mathrm{PrP}^{\mathrm{Sc}}$ using the same principle by which prions propagate during the disease. Both take advantage of the capacity of $\mathrm{PrP}^{\mathrm{Sc}}$ to seed the conversion of $\mathrm{PrP}^{\mathrm{C}}$ into the abnormal form and employ a mechanical force to fragment the $\mathrm{PrP}^{\mathrm{Sc}}$ aggregates, leading to the cyclic amplification of the prion replication process. These procedures enable specific detection of very small quantities of $\mathrm{PrP}^{\mathrm{Sc}}$ in tissues and biological fluids, likely approaching the levels of single particles of $\mathrm{PrP}^{\mathrm{Sc}}$. Both PMCA and RT-QuIC have been used to detect CWD prions at high sensitivity and specificity in various tissues, fluids, and excreta (Pritzkow, Morales \& Soto, 2014; Cheng et al., 2016; Kramm et al., 2017). Moreover, both PMCA (Saborio et al., 2001) and RT-QuIC (Orrú et al., 2017) have been reproduced extensively by many investigators around the world, and these technologies are currently being used in the diagnosis of human prion diseases in the USA and Europe. PMCA was developed first as a universal strategy for amplification of protein misfolding and RT-QuIC is basically a specific format of PMCA to carry out the process of amplification. In prion diseases, PMCA is normally done using brain homogenate as substrate for prion replication, using sonication as a mechanical force to break the aggregates in order to speed up the process, and traditionally utilizes WB for detection of the product. Conversely, RT-QuIC uses purified recombinant prion protein as a substrate, shaking as a fragmentation force, and fluorescence from an amyloid-binding dye as a readout. The main differences between PMCA and RT-QuIC in the context of prion replication is that PMCA reproduces better the biology of the disease, since the $\mathrm{PrP}^{\mathrm{Sc}}$ generated after amplification is fully infectious and maintains the main features of prions, including strain diversity and the species barrier. On the contrary, RT-QuIC does not result in infectious material and does not reproduce strain features 


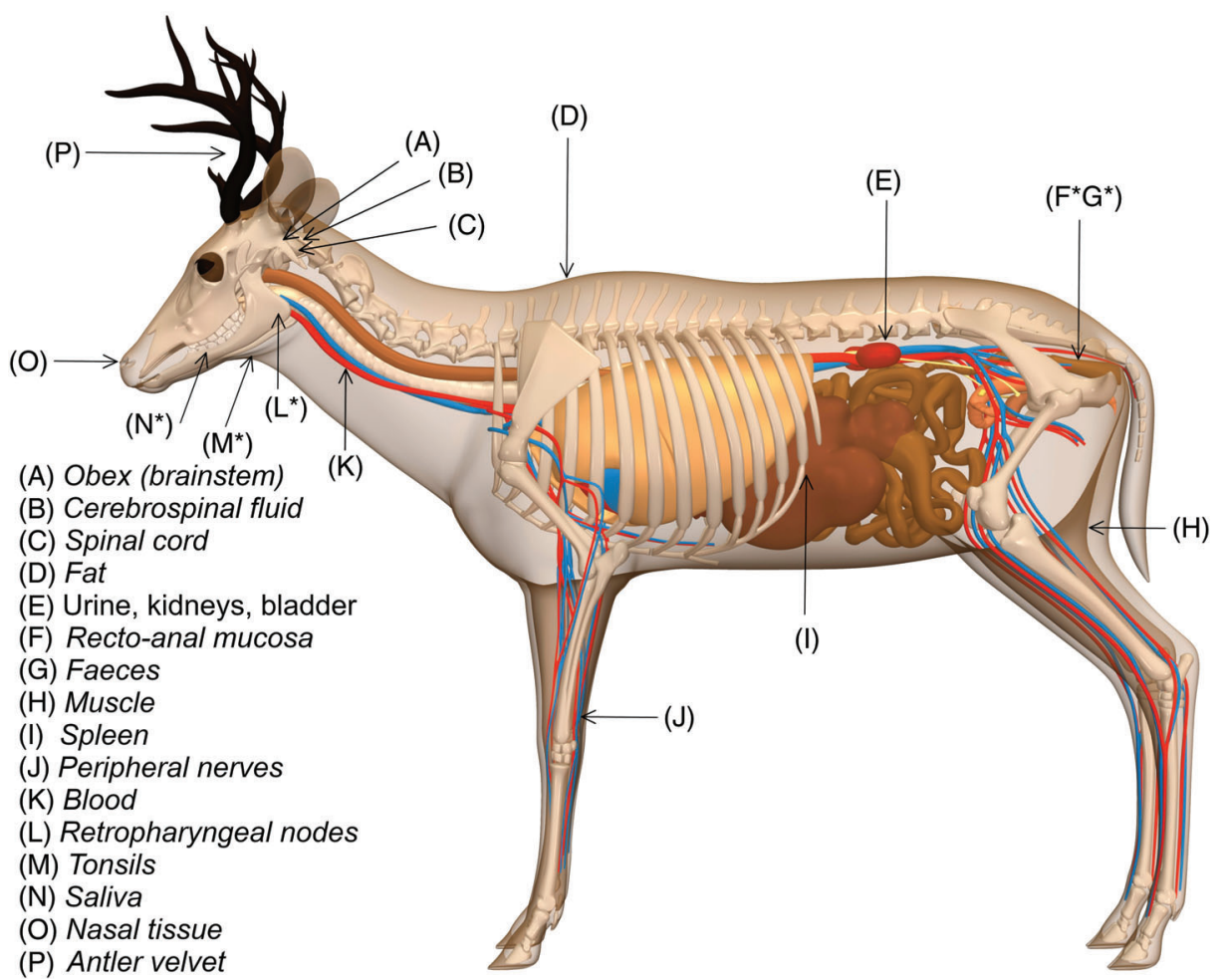

Fig. 6. Detection of Chronic Wasting Disease (CWD) in cervid tissues. Distribution of deer tissues used in CWD detection. (A) obex and brainstem (Haley et al., 201 1); (B) cerebrospinal fluid (Haley et al., 2013); (C) spinal cord (Baeten et al., 2007); (D) fat (Race et al., 2009); (E) urine, kidneys, bladder (Haley \& Hoover, 2015); (F) lymphoid tissue in the intestines including intestinal and rectoanal mucosa (Haley et al., 2011); (G) faeces (Tamgüney et al., 2009); (H) muscle (Angers et al., 2009); (I) spleen (Sigurdson et al., 2002); (J) peripheral nerves (Seelig et al., 2011); (K) blood (Mathiason et al., 2006); (L) medial retropharyngeal lymph nodes (Sigurdson et al., 2002); (M) tonsils (Sigurdson et al., 2002); (N) saliva (Mathiason et al., 2006); (O) nasal tissues (Haley et al., 2016); (P) antler velvet (Angers et al., 2009). Asterisks indicate whether sensitivity is $>50 \%$ based on Haley \& Richt (2017).

or the species barrier. Although a limitation in the study of prion biology, the lack of generation of infectivity by RT-QuIC might be an advantage for its application in routine detection, along with the fact that this assay is more practical for high-throughput screening.

A comparison of CWD detection methods found that all diagnostic methods (IHC, ELISA, WB, PMCA, and RT-QuIC) can successfully detect CWD infection post-mortem in advanced, terminal phases (McNulty et al., 2019). However, classic diagnostic methods, IHC, ELISA, and $\mathrm{WB}$, failed to detect prion deposition at low concentrations, such as the expected amounts during the early phase of prion replication. By contrast, PMCA and RT-QuIC successfully detected prion presence even at very low concentrations, undetectable by traditional methods (McNulty et al., 2019). Thus, considering their insufficient sensitivity for diagnosis in acute phases, IHC, ELISA, and WB should not be used alone for early, asymptomatic CWD surveillance. Nevertheless, neither PMCA or RT-QuIC is yet employed in CWD surveillance, and both are still considered experimental (Gillin \& Mawdsley, 2018). Thus, diagnostic uncertainty, direction of uncertainty (false-negative and false-positive rates), and consistent communication of the biological relevance of detection limits among diagnostic methods should be incorporated in reporting and analyses of GWD epidemiology.

CWD prions have been detected in several tissues of white-tailed deer (Fig. 6). However, tissue samples from the brain (obex) and medial retropharyngeal lymph nodes are the tissues most commonly used in IHG and WB analyses to detect the pathological accumulation of $\operatorname{PrP}^{\mathrm{Sc}}$ (Haley \& Richt, 2017). Sampling these tissues, however, is highly invasive and requires post-mortem or expensive animal handling that limits the extent of samples available. New sampling strategies could be explored in routine surveillance programs, including ultrasensitive methods for prion detection and the used of less-invasive samples such as scat, saliva, or blood (Haley et al., 2011).

Recently, IHC detection of $\operatorname{PrP}^{\mathrm{Sc}}$ in rectal biopsy was evaluated as ante-mortem test (Spraker et al., 2009; Thomsen et al., 2012; Monello et al., 2013). The diagnostic sensitivity of this assay was variable depending on the genotype of the animal and disease progression at the time of sample collection, ranging from 36 to $100 \%$ (Thomsen et al., 2012). Low sensitivity was observed in animals in the early stage of infection when the obex was negative for $\operatorname{PrP}^{\mathrm{Sc}}$ and positive staining was only detected in medial retropharyngeal lymph nodes (Thomsen et al., 2012). Furthermore, although rectal 
biopsy is relatively simple, it is still an invasive and expensive procedure.

Infectivity studies in deer or transgenic mice expressing the cervid prion protein have shown the presence of infectious materials in a large variety of tissues, including central nervous system tissues, peripheral nerves, lympho-reticular organs, gastro-intestinal tissues and skeletal muscle (Haley \& Hoover, 2015). Infectivity was also found in various biological and excretory fluids, including blood, saliva, urine, and faeces (Haley et al., 2011; Kramm et al., 2017). However, it is likely that the quantity of $\mathrm{PrP}^{\mathrm{Sc}}$ present in these fluids is very small, orders of magnitude below the level of sensitivity of the commonly used ELISA and WB assays. Considering that PMCA can detect CWD in blood of infected cervids at the asymptomatic stage, this diagnostic method could be considered as an alternative for CWD detection and surveillance in biological and environmental samples (Kramm et al., 2017).

\section{GONGLUSIONS}

(1) Prions represent a unique type of wildlife pathogen that exhibit exceptional biological properties and large potential threats to wildlife conservation and human and animal health.

(2) Our understanding of transmissible spongiform encephalopathies (TSEs) has advanced dramatically because of CWD (Goñi et al., 2015). CWD has not been confirmed as a zoonotic disease, but research in this arena is still on-going.

(3) From an ecological perspective, control strategies could consider adopting new, ultrasensitive CWD detection procedures in biotic and abiotic reservoirs, management that confronts the interface of captive and wild cervids, restoration of natural predators of CWD reservoirs, and deer density and landscape modification to reduce CWD spread and prevalence.

(4) A more mature understanding of CWD detectability via modern ultrasensitive diagnostic methods would justify the cautionary use of previous epidemiological models based on data from low-sensitivity methods (e.g. ELISA).

(5) The elusive properties of prions have limited the study of their ecology in wild reservoirs, at least compared to other pathogens, and little is known regarding the predictability of prion disease spread among species and areas using classic methods in wildlife disease epidemiology and disease ecology.

(6) Multiscale ecological studies are necessary to untangle the ecological properties of prions at different temporal and geographic scales to understand their natural history in wildlife.

\section{AGKNOWLEDGMENTS}

L.E.E. was supported by the Virginia Tech College of Natural Resources and the Environment Startup Funds and the Virginia Tech Destination Areas Rural Health Seed Grant \#J0788219. C.S. was supported by NIH grant P01AI077774. We thank Manuel Jara for the cladogram of cervids and Sami Livingston for the drawings in Figure 2. Any use of trade, firm, or product names is for descriptive purposes only and does not imply endorsement by the U.S. Government.

\section{CONFLICT OF INTEREST}

C.S. is Founder, Chief Scientific Officer, and majority shareholder of Amprion Inc., a biotech company aiming to commercialize of PMCA and RT-QuIC technologies for highly sensitive detection of misfolded proteins implicated in various neurodegenerative diseases, including CWD. The University of Texas Health Science Center at Houston holds several patent applications related to the PMCA technology which have been licensed to Amprion Inc.

\section{REFERENCES}

Angers, R. G., Kang, H.-E., Napier, D., Browning, S., Seward, T., Mathiason, C., Balachandran, A., McKenzie, D., Castilla, J., Soto, C., Jewell, J., Graham, C., Hoover, E. A. \& Telling, G. C. (2010). Prion strain mutation determined by prion protein conformational compatibility and primary structure. Science 328, 1154-1158.

Angers, R. C., Seward, T. S., Napier, D., Green, M., Hoover, E., Spraker, T., O'Rourke, K., Balachandran, A. \& Telling, G. C. (2009). Chronic wasting disease prions in elk antler velvet. Emerging Infectious Diseases 15, 696-703.

Babelhadj, B., Di Bari, M. A., Pirisinu, L., Chiappini, B., Gaouar, S. B. S. Riccardi, G., Marcon, S., Agrimi, U., Nonno, R. \& Vaccari, G. (2018). Prion disease in dromedary camels, Algeria. Emerging Infectious Diseases 24, 1029-1036.

Baeten, L. A., Powers, B. E., Jewell, J. E., Spraker, T. R. \& Miller, M. W. (2007). A natural case of chronic wasting disease in a free-ranging moose (Alces alces shirasi). Joumal of Wildlife Diseases 43, 309-314.

Bancroft, B. A., Han, B. A., Searle, C. L., Biga, L. M., Olson, D. H., Kats, L. B., LAwLer, J.J. \& Blaustein, A. R. (2011). Species-level correlates of susceptibility to the pathogenic amphibian fungus Batrachochytrium dendrobatidis in the United States. Biodiversity and Conservation 20, 1911-1920.

Barber-Meyer, S. M. \& White, P. J. (2005). Survey of selected pathogens and blood parameters of northern Yellowstone elk: wolf sanitation effect implications. Wildlife Research 158, 369-381.

Barrette, C. (1977). Fighting behavior of Muntjac and the evolution of antlers. Evolution 31, 169-176.

Barria, M. A., Libori, A., Mitchell, G. \& Head, M. W. (2018). Susceptibility of human prion protein to conversion by chronic wasting disease prions. Emerging Infectious Diseases 24, 2-9.

Barria, M. A., Telling, G. G., Gambetti, P., Mastrianni, J. A. \& Soto, G. (2011). Generation of a new form of human PrPSc in vitro by interspecies transmission from cervid prions. Fournal of Biological Chemistry 286, 7490-7495.

Bartelt-Hunt, S. L. \& Bartz, J. C. (2013). Behavior of prions in the environment: implications for prion biology. PLoS Pathogens 9, e1003113.

Bartz, J. C., Marsh, R. F., McKenzie, D. I. \& Aiken, J. M. (1998). The host range of chronic wasting disease is altered on passage in ferrets. Virology 251, 297-301.

Benavides, J. A., Valderrama, W. \& Streicker, D. G. (2016). Spatial expansions and travelling waves of rabies in vampire bats. Proceedings of the Royal Society B 283, 20160328.

Benestad, S. L., Mitchell, G., Simmons, M., Ytrehus, B. \& Vikøren, T. (2016). First case of chronic wasting disease in Europe in a Norwegian free-ranging reindeer. Veterinary Research 47, 1-7.

Bian, J., Christiansen, J. R., Moreno, J. A., Kane, S. J., Khaychuk, V., Gallegos, J., Kim, S. \& Telling, G. C. (2019). Primary structural differences at residue 226 of deer and elk PrP dictate selection of distinct CWD prion strains in gene-targeted mice. Proceedings of the National Academy of Sciences USA $\mathbf{1 1 6}$ $12478-12487$ 
Blanchong, J. A., Samuel, M. D., Scribner, K. T., Weckworth, B. V., LangenberG, J. A. \& Filcek, K. B. (2008). Landscape genetics and the spatial distribution of chronic wasting disease. Biology Letters 4, 130-133.

Blumhardt, M. (2018). Chronic wasting disease linked to Fort Collins for 50 years. Fort Collins. Coloradoan. https://www.coloradoan.com/story/news/2018/08/ 23/cdc-tse-mad-cow-chronic-wasting-disease-linked-fort-collins/878097002/ Accessed 05.02.2019

Bollinger, D. T., Caley, D. P., Merrill, D. E., Messier, D. F., Miller, D. M. W., Samuel, D. M. D. \& Vanopdenbosch, D. E. (2004). Expert Scientific Panel on Chronic Wasting Disease. Canadian Cooperative Wildlife Health Centre, Saskatoon.

Bunk, S. (2004). Chronic wasting disease - Prion disease in the wild. PLoS Biology 2, 427.

Carlson, G. M., Hopkins, M. G., Nguyen, N. T., Richards, B. J., Walsh, D. P. \& Walter, W. D. (2018). Chronic Wasting Disease: Status, Science, and Management. U.S. Geological Survey, Madison.

CDC (2018a). Prevention. Chronic Wasting Disease (CWD). Centers for Disease Control and Prevention, National Center for Emerging and Zoonotic Infectious Diseases. https://www.cdc .gov/prions/cwd/prevention.html Accessed 10.02.2019.

CDC (2018b). Prion diseases. Centers for Disease Control and Prevention, National Center for Emerging and Zoonotic Infectious Diseases (NCEZID), Division of High-Consequence Pathogens and Pathology (DHCPP). https://www.cdc.gov/prions/ Accessed 02.10.2019.

CDC (2019). Occurrence. Chronic Wasting Disease (CWD). Centers for Disease Control and Prevention, National Center for Emerging and Zoonotic Infectious Diseases. https://www.cdc .gov/prions/cwd/occurrence.html Accessed 16.08.2019.

Cheng, Y. C., Hannaoui, S., John, T. R., Dudas, S., Czub, S. \& Gilch, S. (2016). Early and non-invasive detection of chronic wasting disease prions in elk feces by real-time quaking induced conversion. PLoS One 11, 1-18.

Clank, J. D., Huber, D. \& Servheen, C. (2002). Bear reintroductions: lessons and challenges. Ursus 13, 335-345.

Clements, G. M., Hygnstrom, S. E., Gilsdorf, J. M., BaAsch, D. M., Clements, M. J. \& Vercauteren, K. G. (2011). Movements of white-tailed deer in riparian habitat: implications for infectious diseases. Journal of Wildlife Management 75, $1436-1442$.

Conner, M. M., Ebinger, M. R., Blanchong, J. A. \& Cross, P. C. (2008). Infectious disease in cervids of North America: data, models, and management challenges. Annals of the New York Academy of Sciences 1134, 146-172.

Conner, M. M., McCarty, G. W. \& Miller, M. W. (2000). Detection of bias in harvest-based estimates of chronic wasting disease prevalence in mule deer. Fournal of Wildlife Diseases 36, 691-699.

Conner, M. M. \& Miller, M. W. (2004). Movement patterns and spatialo epidemiology of a prion disease in mule deer population units. Ecological Applications $14,1870-1881$

Creech, T. G., Cross, P. C., Scurlock, B. M., Maichak, E. J., Rogerson, J. D., Henningsen, J. C. \& Creel, S. (2012). Effects of low-density feeding on elk - fetus contact rates on Wyoming feedgrounds. Fournal of Wildlife Management 76, 877-886.

Crowell, J., Hughson, A., Caughey, B. \& Bessen, R. A. (2015). Host determinants of prion strain diversity independent of prion protein genotype. Fournal of Virology $\mathbf{8 9}$, $10427-10441$.

CWD Alliance (2019). North American Location for CWD Newes and Information. Chronic Wasting Disease Alliance. http://cwd-info.org/map-chronic-wasting-disease-innorth-america/ Accessed 17.02.2019.

Czub, S., Schulz-Schaeffer, W., Stahl-Hennig, C., Beekes, M., Schaetzl, H. \& Motzkus, D. (2017). First evidence of intracranial and peroral transmission or chronic wasting disease (CWD) into Cynomolgus macaques: a work in progress. In Prion 2017 Deciphering Neurodegenerative Disorders. Taylor \& Francis, Edingurgh.

Denkers, N. D., Hayes-Klug, J., Anderson, K. R., Seelig, D. M., Haley, N. J., Dahmes, S. J., Osborn, D. A., Miller, K. V., Warren, R. J., Mathiason, C. K. \& Hoover, E. A. (2013). Aerosol transmission of chronic wasting disease in white-tailed deer. Fournal of Virology 87, 1890-1892.

Duque-Velásquez, C., Kim, C., Herbst, A., Daude, N., Garza, M. C., Wille, H., Aiken, J. \& McKenzie, D. (2015). Deer prion proteins modulate the emergence and adaptation of chronic wasting disease strains. Fournal of Virology 89, 12362-12373.

Edmunds, D. R., Albeke, S. E., Grogan, R. G., Lindzey, F. G., LegG, D. E., Cook, W. E., Schumaker, B. A., Kreeger, T. J. \& Cornish, T. E. (2018). Chronic wasting disease influences activity and behavior in white-tailed deer. Fournal of Wildlife Management 82, 138-154.

Edmunds, D. R., Kauffman, M. J., Schumaker, B. A., Lindzey, F. G., Cook, W. E., Kreeger, T. J., Grogan, R. G. \& Cornish, T. E. (2016). Chronic wasting disease drives population decline of white-tailed deer. PLoS One 11, 1-19.

Edwards, G., Zhao, J., Dash, P. K., Soto, C. \& Moreno-Gonzalez, I. (2019). Traumatic brain injury induces tau aggregation and spreading. Fournal of Neurotrauma. https://www.liebertpub.com/doi/pdf/10.1089/neu.2018.6348. [Epub ahead of print].

Escobar, L. E. \& Craft, M. E. (2016). Advances and limitations of disease biogeography using ecological niche modeling. Frontiers in Microbiology 7, 1174.

Estrada-Peña, A., Ostfeld, R. S., Peterson, A. T., Poulin, R. \& de la Fuente, J. (2014). Effects of environmental change on zoonotic disease risk: an ecological primer. Trends in Parasitology 30, 205-214.
Evans, M. V., Dallas, T. A., Han, B. A., Murdock, C. C. \& Drake, J. M. (2017). Data-driven identification of potential zika virus vectors. eLife $6,1-38$.

Evans, T. S., Schuler, K. L. \& WAlter, W. D. (2014). Surveillance and monitoring of white-tailed deer for chronic wasting disease in the northeastern United States. fournal of Fish and Wildlife Management 5, 387-393.

Evira (2018). Moose Found Dead in Forest with Chronic Wasting Disease. Finnish Food Safety Authority. https://www.evira.fi/en/animals/current_issues/2018/moosefound-dead-in-forest-with-chronic-wasting-disease/ Accessed 03.08.2018.

Farnsworth, M. L., Hoeting, J. A., Hobbs, N. T. \& Miller, M. W. (2006). Linking chronic wasting disease to mule deer movement scales: a hierarchical Bayesian approach. Ecological Applications 16, 1026-1036.

Fischer, J. W., Phillips, G. E., Nichols, T. A. \& VerCauteren, K. C. (2013). Could avian scavengers translocate infectious prions to disease-free areas initiating new foci of chronic wasting disease? Prion 7, 263-266.

Fox, K. A., Jewell, J. E., Williams, E. S. \& Miller, M. W. (2006). Patterns of $\mathrm{PrPCWD}$ accumulation during the course of chronic wasting disease infection in orally inoculated mule deer (Odocoileus hemionus). Fournal of General Virology 87, $3451-3461$.

Geist, V. (1986). New evidence of high frequency of antler wounding in cervids. Canadian Foumal of Zoology 64, 380-384.

Georgsson, G., Sigurdarson, S. \& Brown, P. (2006). Infectious agent of sheep scrapie may persist in the environment for at least 16 years. Fournal of General Virology 87, $3737-3740$

Gilbert, C., Ropiquet, A. \& Hassanin, A. (2006). Mitochondrial and nuclear phylogenies of Cervidae (Mammalia, Ruminantia): systematics, morphology, and biogeography. Molecular Phylogenetics and Evolution 40, 101-117.

Gillin, C. M. \& Mawdsley, J. R. (2018). AFWA Technical Report on Best Management Practices for Prevention, Surveillance, and Management of Chronic Wasting Disease. Association of Fish and Wildlife Agencies, Washington, DC.

Goñi, F., Mathiason, C. K., Yim, L., Wong, K., Hayes-Klug, J., Nalls, A., Peyser, D., Estevez, V., Denkers, N., Xu, J., Osborn, D. A., Miller, K. V., Warren, R. J., Brown, D. R., Chabalgoity, J. A., et al. (2015). Mucosal immunization with an attenuated Salmonella vaccine partially protects white-tailed deer from chronic wasting disease. Vaccine 33, 726-733.

Gortázar, C., Reperant, L. A., Kuiken, T., de la Fuente, J., Boadella, M., Martínez-Lopéz, B., Ruiz-Fons, F., Estrada-Peña, A., Drosten, C., Medley, G., Ostfeld, R., Peterson, A. T., Vercauteren, K. C., Menge, C., Artois, M., et al. (2014). Crossing the interspecies barrier: opening the door to zoonotic pathogens. PLoS Pathogens 10, e1004129.

Grear, D. A., Samuel, M. D., Scribner, K. T., Weckworth, B. V. \& LANGENBERG, J. A. (2010). Influence of genetic relatedness and spatial proximity on chronic wasting disease infection among female white-tailed deer. Fournal of Applied Ecology 47, 532-540.

Greenlee, J. J., Smith, J. D. \& Kunkle, R. A. (2011). White-tailed deer are susceptible to the agent of sheep scrapie by intracerebral inoculation. Veterinary Research 42, 107.

Guiroy, D. C., Williams, E. S., Song, K. J., Yanagihara, R. \& Gajdusek, D. C. (1993). Fibrils in brains of Rocky Mountain elk with chronic wasting disease contain scrapie amyloid. Acta Neuropathologica 86, 77-80.

Habib, T. J., Merrill, E. H., Pybus, M. J. \& Coltman, D. W. (2011). Modelling landscape effects on density-contact rate relationships of deer in eastern Alberta: implications for chronic wasting disease. Ecological Modelling 222, 2722-2732.

Haley, N. J. \& Hoover, E. A. (2015). Chronic wasting disease of cervids: current knowledge and future perspectives. Annual Review of Animal Biosciences 3, 305-325.

Haley, N. J., Mathiason, C. K., Carver, S., Zabel, M., Telling, G. C. \& Hoover, E. A. (2011). Detection of chronic wasting disease prions in salivary, urinary, and intestinal tissues of deer: potential mechanisms of prion shedding and transmission. Fournal of Virology 85, 6309-6318.

Haley, N. J., Mathiason, C. K., Zabel, M. D., Telling, G. C. \& Hoover, E. A. (2009). Detection of sub-clinical CWD infection in conventional test-negative deer long after oral exposure to urine and feces from CWD+ deer. PLoS One 4, e7990.

Haley, N. J. \& Richt, J. (2017). Evolution of diagnostic tests for chronic wasting disease, a naturally occurring prion disease of cervids. Pathogens $6,35$.

Haley, N. J., Siepker, C., Walter, W. D., Thomsen, B. V., Greenlee, J. J., Lehmkuhl, A. D. \& Richt, J. A. (2016). Antemortem detection of chronic wasting disease prions in nasal brush collections and rectal biopsy specimens from white-tailed deer by Real-Time Quaking-Induced Conversion. Fournal of Clinical Microbiology 54, 1108-1116.

Haley, N. J., Van De Motter, A., Carver, S., Henderson, D., Davenport, K., Seelig, D. M., Mathiason, C. \& Hoover, E. (2013). Prion-seeding activity in cerebrospinal fluid of deer with chronic wasting disease. PLoS One 8, 1-12.

Hamir, A. N., Cutlip, R. C., Miller, J. M., Williams, E. S., Stack, M. J., Miller, M. W., O'rourke, K. I. \& Chaplin, M. J. (2001). Preliminary findings on the experimental transmission of chronic wasting disease agent of mule deer to cattle. Fournal of Veterinary Diagnostic Investigation 13, 91-96.

Hamir, A. N., Greenlee, J. J., Nicholson, E. M., Kunkle, R. A., Richt, J. A., Miller, J. M. \& Hall, M. (2011). Experimental transmission of chronic wasting 
disease (CWD) from elk and white-tailed deer to fallow deer by intracerebral route: final report. Canadian Fournal of Veterinary Research 75, 152-156.

Hamir, A. N., Kunkle, R. A., Cutlip, R. C., Miller, J. M., O’Rourke, K. I., Williams, E. S., Miller, M. W., Stack, M. J., Chaplin, M. J. \& Richt, J. A. (2005). Experimental transmission of chronic wasting disease agent from mule deer to cattle by the intracerebral route. Fournal of Veterinary Diagnostic Investigation 17, $276-281$

Hamir, A. N., Kunkle, R. A., Cutlip, R. C., Miller, J. M., Williams, E. S. \& Richt, J. A. (2006). Transmission of chronic wasting disease of mule deer to Suffolk sheep following intracerebral inoculation. Fournal of Veterinary Diagnostic Investigation 18, 558-565.

Hamir, A. N., Kunkle, R. A., Miller, J. M., Cutlip, R. C., Richt, J. A., Kehrli, M. E. \& Williams, E. S. (2007). Age-related lesions in laboratory-confined raccoons (Procyon lotor) inoculated with the agent of chronic wasting disease of mule deer. Fournal of Veterinary Diagnostic Investigation 19, 680-686.

Hamir, A. N., Miller, J. M., Cutlip, R. C., Kunkle, R. A., Jenny, A. L., Stack, M. J., Chaplin, M. J. \& Richt, J. A. (2004). Transmission of shepp scrapie to elk (Cervus elaphus nelsoni) by intracerebral inoculation: final outcome of the experiment. fournal of Veterinary Diagnostic Investigation 16, 316-321.

Hamir, A. N., Miller, J. M., Kunkle, R. A., Hall, S. M. \& Richt, J. A. (2007). Susceptibility of cattle to first-passage intracerebral inoculation with chronic wasting disease agent from white-tailed deer. Veterinary Pathology 44, 487-493.

Hamir, A. N., Richt, J. A., Miller, J. M., Kunkle, R. A., Hall, S. M., Nicholson, E. M., O’Rourke, K. I., Greenlee, J. J. \& Williams, E. S. (2008). Experimental transmission of chronic wasting disease (CWD) of elk (Cervus elaphus nelsoni), white-tailed deer (Odocoileus virginianus), and mule deer (Odocoileus hemionus hemionus) to white-tailed deer by intracerebral route. Veterinary Pathology 45 , $297-306$.

Han, B. A., Schmidt, J. P., Alexander, L. W., Bowden, S. E., Hayman, D. T. S. \& Drake, J. M. (2016). Undiscovered bat hosts of filoviruses. PLoS Neglected Tropical Diseases 10, 1-10.

Han, B. A., Schmidt, J. P., Bowden, S. E. \& Drake, J. M. (2015). Rodent reservoirs of future zoonotic diseases. Proceedings of the National Academy of Sciences USA 112, 201501598

Haybaeck, J., Heikenwalder, M., Klevenz, B., Schwarz, P., Margalith, I., Bridel, C., Mertz, K., Zirdum, E., Petsch, B., Fuchs, T. J., Stitz, L. \& Aguzzi, A. (2011). Aerosols transmit prions to immunocompetent and immunodeficient Mice. PLoS Pathogens 7, e1001257.

Heisey, D. M., Mickelsen, N. A., Schneider, J. R., Johnson, G. J., Johnson, C. J., Langenberg, J. A., Bochsler, P. N., Keane, D. P. \& Barr, D. J. (2010). Chronic wasting disease (CWD) susceptibility of several North American rodents that are sympatric with cervid CWD epidemics. Fournal of Virology 84, 210-215.

Henderson, D. M., Davenport, K. A., Haley, N. J., Denkers, N. D., Mathiason, C. K. \& Hoover, E. A. (2015). Quantitative assessment of prion infectivity in tissues and body fluids by real-time quaking-induced conversion. Journal of General Virology 96, 210-219.

Hibler, C. P., Willon, K. L., Spraker, T. R., Miller, M. W., Zink, R. R., DeBuse, L. L., Andersen, E., Schweitzer, D., Kennedy, J. A., Baeten, L. A. Smeltzer, J. F., Salman, M. D. \& Powers, B. E. (2003). Field validation and assessment of an enzyme-linked immunosorbent assay for detecting chronic wasting disease in mule deer, white-tailed deer, and Rocky Mountain elk. Fournal of Veterinary Diagnostic Investigation 15, 311-319.

Hill, A. F. \& Collinge, J. (2004). Prion strains and species barriers. In Prions. A Challenge for Science, Medicine and the Public Health System (eds H. F. Rabenau, J. Cinate and H. W. Doerr), pp. 33-49. Karger, Basel.

Hoввs, N. T. (2006). A model analysis of effects of wolf predation on prevalence of chronic wasting disease. In Elk Populations of Rocky Mountain National Park. National Park Service Report. Washington, D.C. https://leg.mt.gov/content/committees/ interim/2009_2010/environmental_quality_council/minutes/eqc05072010_ex25 .pdf Accessed 16.08.2019.

Holcomb, K. M., Galloway, N. L. \& Mathiason, G. K. (2016). Intra-host mathematical model of chronic wasting disease dynamics in deer (Odocoileus). Prion 10, 377-390.

Hutter, S. E., Brugger, K., Sancho Vargas, V. H., González, R., Aguilar, O., León, B., Tichy, A., Firth, C. L. \& Rubel, F. (2016). Rabies in Costa Rica: documentation of the surveillance program and the endemic situation from 1985 to 2014. Vector-Borne and Zoonotic Diseases 16, 334-341.

Igel-Egalon, A., Béringue, V., Rezaei, H. \& Sibille, P. (2018). Prion strains and transmission barrier phenomena. Pathogens 7, 5 .

Ironside, J. W., Sutherland, K., Bell, J. E., McCardle, L., Barrie, C., Estebeiro, K., Zeidler, M. \& Will, R. G. (1996). A new variant of Creutzfeldt-Jakob disease: neuropathological and clinical features. Cold Spring Harbor Symposia on Quantitative Biology 61, 523-530.

Jakob-Hoff, R. M., MacDiarmid, S. C., Lees, C., Miller, P. S., Travis, D. \& Kock, R. (2014). Manual of Procedures for Wildlife Disease Risk Analysis. Office International des Épizooties, Paris.

Jennelle, C. S., Henaux, V., Wasserberg, G., Thiagarajan, B., Rolley, R. E. \& SAmuel, M. D. (2014). Transmission of chronic wasting disease in Wisconsin white-tailed deer: implications for disease spread and management. PLoS ONE 9 e91043.

Jennelle, C. S., Samuel, M. D., Nolden, C. A. \& Berkley, E. A. (2009). Deer carcass decomposition and potential scavenger exposure to chronic wasting disease. Journal of Wildlife Management 73, 655-662.

Johnson, R. T. (2005). Prion disease. The Lancet Neurology 4, 635-642.

Johnson, C. J., Pedersen, J. A., Chappell, R. J., McKenzie, D. \& Aiken, J. M. 2007). Oral transmissibility of prion disease is enhanced by binding to soil particles. PLoS Pathogens 3, 0874-0881.

Joly, D. O., Ribic, C. A., Langenberg, J. A., Beheler, K., Batha, C. A. Dhuey, B. J., Rolley, R. E., Bartelt, G., Van Deelen, T. R. \& Samuel M. D. (2003). Chronic wasting disease in free-ranging Wisconsin white-tailed deer. Emerging Infectious Diseases 9, 599-601.

Joly, D. O., Samuel, M. D., Langenberg, J. A., Blanchong, J. A., Batha, C. A., Rolley, R. E., Keane, D. P. \& Ribic, C. A. (2006). Spatial epidemiology of chronic wasting disease in Wisconsin white-tailed deer. Fournal of Wildlife Diseases 42, $578-588$.

Kim, T. Y., Shon, H. J., Joo, Y. S., Mun, U. K., Kang, K. S. \& Lee, Y. S. (2005). Additional cases of chronic wasting disease in imported deer in Korea. Fournal of Veterinary Medical Science 67, 753-759.

Kong, O., Huang, S., Zou, W., Vanegas, D., Wang, M., Wu, D., Yuan, J., Zheng, M., Bai, H., Deng, H., Chen, K., Jenny, A. L., Rourke, K. O., Belay, E. D. Schonberger, L. B., et al. (2005). Chronic wasting disease of elk: transmissibility to humans examined by transgenic mouse models. Fournal of Neuroscience 25, 7944-7949.

Kramm, G., Pritzkow, S., Lyon, A., Nichols, T., Morales, R. \& Soto, G. (2017). Detection of prions in blood of cervids at the asymptomatic stage of chronic wasting disease. Scientific Reports 7, 17241

Krumm, C. E., Conner, M. M., Hobbs, N. T., Hunter, D. O. \& Miller, M. W. (2010). Mountain lions prey selectively on prion-infected mule deer. Biology Letters 6 , 209-211.

Kuznetsova, A., Cullingham, C., McKenzie, D. \& Aiken, J. M. (2018). Soil humic acids degrade CWD prions and reduce infectivity. PLoS Pathogens 14, e1007414.

Lee, Y. H., Sohn, H. Y., Kim, M. J., Kim, H. J., Lee, W. Y., Yun, E. I., Tark, D. S., Cho, I. S. \& Balachandran, A. (2013). Strain characterization of the Korean CWD cases in 2001 and 2004. Fournal of Veterinary Medical Science 75, 95-98.

Leslie, D. M. \& Jenkins, K. J. (1985). Rutting mortality among male Rooselvelt elk. Journal of Mammalogy 66, 163-164.

LEvin, S. A. (1992). The problem of pattern and scale in ecology: the Robert H MacArthur award lecture. Ecology 73, 1943-1967.

Luis, A. D., O’Shea, T. J., Hayman, D. T. S., Wood, J. L. N., Cunningham, A. A., Gilbert, A. T., Mills, J. N. \& WebB, C. T. (2015). Network analysis of host-virus communities in bats and rodents reveals determinants of cross-species transmission. Ecology Letters 18, 1153-1162.

Lydekker, R. (1898). The Deer of All Lands: A History of the Family Cervidae, Living and Extinct. R. Ward, London.

Madsen-Bouterse, S. A., Schneider, D. A., Zhuang, D., Dassanayake, R. P., Balachandran, A., Mitchell, G. B. \& O’Rourke, K. I. (2016). Primary transmission of chronic wasting disease versus scrapie prions from small ruminants to transgenic mice expressing ovine or cervid prion protein. fournal of General Virology 97, 2451-2460.

Manjerovic, M. B., Green, M. L., Mateus-Pinilla, N. \& Novakofski, J. (2014) The importance of localized culling in stabilizing chronic wasting disease prevalence in white-tailed deer populations. Preventive Veterinary Medicine 113, 139-145.

Marsh, R. F., Kincaid, A. E., Bessen, R. A. \& Bartz, J. G. (2005). Interspecies transmission of chronic wasting disease prions to squirrel monkeys (Saimiri sciureus). Fournal of Virology 79, 13794-13796.

Mathiason, C. K., Hays, S. A., Powers, J., Hayes-klug, J., Langenberg, J., Dahmes, S. J., Osborn, D. A., Miller, K. V., Warren, R. J., Mason, G. L. \& EDWARD, A. (2009). Infectious prions in pre-clinical deer and transmission of chronic wasting disease solely by environmental exposure. PLoS One 4 e5916.

Mathiason, C. K., Powers, J. G., Dahmes, S. J., Osborn, D. A., Miller, K. V., Warren, R. J., Mason, G. L., Hays, S. A., Hayes-Klug, J., Seelig, D. M., Wild, M. A., Wolfe, L. L., Spraker, T. R., Miller, M. W., Sigurdson, C. J., et al. (2006). Infectious prions in the saliva and blood of deer with chronic wasting disease. Science 314, 133-136.

McNulty, E., Nalls, A. V., Mellentine, S., Hughes, E., Pulscher, L., Hoover, E. A. \& Mathiason, C. K. (2019). Comparison of conventional, amplification and bio-assay detection methods for a chronic wasting disease inoculum pool. PLoS One $14,1-19$.

Meagher, M. \& Phillips, J.R. (1980). Restoration of natural populations of grizzly and black bears in Yellowstone National Park. Bears: Their Biology and Management 5, $152-158$.

Miller, M. W. \& Conner, M. M. (2013). Epidemiology of chronic wasting disease in free-ranging mule deer: spatial, temporal, and demographic influences on observed prevalence patterns. Fournal of Wildlife Diseases 41, 275-290. 
Miller, M. W., Wild, M. A. \& Williams, E. S. (1998). Epidemiology of chronic wasting disease in captive Rocky Mountain elk. Journal of Wildlife Diseases 34, $532-538$.

Monello, R. J., Powers, J. G., Hobbs, N. T., Spraker, T. R., O'Rourke, K. I. \& WILD, M. A. (2013). Efficacy of antemortem rectal biopsies to diagnose and estimate prevalence of chronic wasting disease in free-ranging cow elk (Cervus elaphus nelsoni). Journal of Wildlife Diseases 49, 270-278.

Moore, S. J., Smith, J. D., Richt, J. A. \& Greenlee, J. J. (2019). Raccoons accumulate PrP Sc after intracranial inoculation of the agents of chronic wasting disease or transmissible mink encephalopathy but not atypical scrapie. Fournal of Veterinary Diagnostic Investigation 31, 200-209.

Moore, R. A., Vorberg, I. \& Priola, S. A. (2005). Species barriers in prion diseases: brief review. In Infectious Diseases from Nature: Mechanisms of Viral Emergence and Persistence (eds C. J. Peters and C. H. Calisher). Springer, Vienna.

Moore, S. J., West Greenlee, M. H., Kondru, N., Manne, S., Smith, J. D., Kunkle, R. A., Kanthasamy, A. \& Greenlee, J. J. (2017). Experimental transmission of the chronic wasting Disease agent to swine after oral or intracranial inoculation. Fournal of Virology 91, e00926-17.

Nalls, A. V., McNulty, E., Powers, J., Seelig, D. M., Hoover, C., Haley, N. J., Hayes-Klug, J., Anderson, K., Stewart, P., Goldmann, W., Hoover, E. A. \& Mathiason, C. K. (2013). Mother to offspring transmission of chronic wasting disease in reeves' Muntjac deer. PLoS One 8, e71844.

Nichols, T. A., Fischer, J. W., Spraker, T. R., Kong, Q. \& VerCauteren, K. C. (2015). CWD prions remain infectious after passage through the digestive system of coyotes (Canis latrans). Prion 9, 367-375.

Nobert, B. R., Merrill, E. H., Pybus, M. J., Bollinger, T. K. \& Hwang, Y. T. (2016). Landscape connectivity predicts chronic wasting disease risk in Canada. fournal of Applied Ecology 53, 1450-1459.

Olival, K. J., Hosseini, P. R., Zambrana-Torrelio, C., Ross, N., Bogich, T. L. \& DAszAK, P. (2017). Host and viral traits predict zoonotic spillover from mammals. Nature 546, 646-650.

Olszowy, K. M., Lavelle, J., Rachfal, K., Hempstead, S., Drouin, K., Darcy, J. M., Reiber, C. \& Garruto, R. M. (2014). Six-year follow-up of a point-source exposure to CWD contaminated venison in an Upstate New York community: risk behaviours and health outcomes 2005-2011. Public Health 128, 860-868.

Orrú, C. D., Groveman, B. R., Hughon, A. G., Manca, M., Raymond, L. D., Raymond, G. J., Campbell, K. J., Anson, K. J., Kraus, A. \& Caughey, B. (2017). RT-QuIC assays for prion disease detection and diagnostics. Methods and Protocols 1658, 185-203.

Orrú, C. D., Groveman, B. R., Raymond, L. D., Hughson, A. G., Nonno, R., Zou, W., Ghetti, B. \& Gambetti, P. (2015). Bank vole prion protein as an apparently universal substrate for RT-QuIC-based detection and discrimination of prion strains. PLoS Pathogens 11, e1004983.

Osterholm, M. T., Anderson, C. J., Zabel, M. D., Scheftel, J. M., Moore, K. A. \& Appleby, B. S. (2019). Chronic wasting disease in cervids: implications for prion transmission to humans and other animal species. mBio 10, 608.

Oyer, A. M., Mathews, N. E. \& Skuldt, L. H. (2007). Long-distance mvement of a white-tailed deer away from a chronic wasting disease area. Journal of Wildife Management 71, 1635-1638.

Packer, C., Holt, R. D., Hudson, P. J., Lafferty, K. D. \& Dobson, A. P. (2003). Keeping the herds healthy and alert: implications of predator control for infectious disease. Ecology Letters 6, 797-802.

Perrott, M. R., Sigurdson, C. J., Mason, G. L. \& Hoover, E. A. (2013). Mucosal transmission and pathogenesis of chronic wasting disease in ferrets. Fournal of General Virology 94, 432-442.

Peters, J., Miller, J. M., Jenny, A. L., Peterson, T. L. \& Carmichael, K. P. (2000). Immunohistochemical diagnosis of chronic wasting disease in preclinically affected elk from a captive herd. Fournal of Veterinary Diagnostic Investigation 12, $579-582$.

Peterson, A. T. (2014). Mapping Disease Transmission Risk. Johns Hopkins University Press, Baltimore.

Piaggio, A. J., Russell, A. L., Osorio, I. A., Jiménez Ramírez, A., Fischer, J. W., Neuwald, J. L., Tibbels, A. E., Lecuona, L. \& McCracken, G. F. (2017). Genetic demography at the leading edge of the distribution of a rabies virus vector. Ecology and Evolution 7, 5343-5351.

Plowright, R. K., Sokolow, S. H., Gorman, M. E., Daszak, P. \& Foley, J. E. (2008). Causal inference in disease ecology: investigating ecological drivers of disease emergence. Frontiers in Ecology and the Environment 6, 420-429.

Plummer, I. H., Johnson, C. J., Chesney, A. R., Pedersen, J. A. \& Samuel, M. D. (2018). Mineral licks as environmental reservoirs of chronic wasting disease prions. PLoS One 13, 1-13.

Plummer, I. H., Wright, S. D., Johnson, C. J., Pedersen, J. A. \& Samuel, M. D. (2017). Temporal patterns of chronic wasting disease prion excretion in three cervid species. Fournal of General Virology 98, 1932-1942.

Potapov, A., Merrill, E. \& Lewis, M. A. (2012). Wildlife disease elimination and density dependence. Proceedings of the Royal Society B 279, 3139-3145.
Potapov, A., Merrill, E., Pybus, M., Coltman, D. \& Lewis, M. A. (2013). Chronic wasting disease: possible transmission mechanisms in deer. Ecological Modelling 250, $244-257$.

Pritzkow, S., Morales, R., Lyon, A., Concha-Marambio, L., Urayama, A. \& Sото, C. (2018). Efficient prion disease transmission through common environmental materials. Fournal of Biological Chemistry 293, 3363-3373.

Pritzkow, S., Morales, R., Moda, F., Khan, U., Telling, G. C., Hoover, E. \& Sото, C. (2015). Grass plants bind, retain, uptake, and transport infectious prions. Cell Reports 11, 1168-1175.

Pritzkow, S., Morales, R. \& Soto, C. (2014). Efficient transmission of prion disease through environmental contamination. Prion 8, 81-82.

Prusiner, S. B. (1982). Novel proteinaceous infectious particles cause scrapie. Science 216, 136-144.

Prusiner, S. B. (1998). Prions. Proceedings of the National Academy of Sciences USA 95, $13363-13383$.

Race, B., Meade-White, K., Race, R. \& Chesebro, B. (2009). Prion infectivity in fat of deer with chronic wasting disease. Fournal of Virology 83, 9608-9610.

Race, B., Williams, K., Hughson, A. G., Jansen, C., Parchi, P., Rozemuller, A. J. M. \& Chesebro, B. (2018). Familial human prion diseases associated with prion protein mutations $\mathrm{Y} 226 \mathrm{X}$ and G131V are transmissible to transgenic mice expressing human prion protein. Acta Neuropathologica Communications 6, 13.

Race, B., Williams, K., Orrú, C. D., Hughson, A. G., Lubke, L. \& Chesebro, B. (2018). Lack of transmission of chronic wasting disease to Cynomolgus macaques. Fournal of Virology 92, e00550-18.

Raymond, G. J., Raymond, L. D., Meade-White, K. D., Hughson, A. G., Favara, C., Gardner, D., Williams, E. S., Miller, M. W., Race, R. E. \& Caughey, B. (2007). Transmission and adaptation of chronic wasting disease to hamsters and transgenic mice: evidence for strains. Fournal of Virology 81, 4305-4314.

Rees, E. E., Merrill, E. H., Bollinger, T. K., Hwang, Y. T., Pybus, M. J. \& Coltman, D. W. (2012). Targeting the detection of chronic wasting disease using the hunter harvest during early phases of an outbreak in Saskatchewan, Canada. Preventive Veterinary Medicine 104, 149-159.

Robinson, S. J., Samuel, M. D., Johnson, C. J., Adams, M. \& McKenzie, D. I. (2012). Emerging prion disease drives host selection in a wildlife population. Ecological Applications 22, 1050-1059.

Robinson, S. J., Samuel, M. D., O’Rourke, K. I. \& Johnson, C. J. (2012). The role of genetics in chronic wasting disease of North American cervids. Prion 6, 153-162.

Rubenstein, R., Chang, B., Grinkina, N., Drummond, E., Davies, P., Ruditzky, M., Sharma, D., Wang, K. \& Wisniewski, T. (2017). Tau phosphorylation induced by severe closed head traumatic brain injury is linked to the cellular prion protein. Acta Neuropathologica Communications 5, 1-17.

Saborio, G. P., Permanne, B. \& Soto, G. (2001). Sensitive detection of pathological prion protein by cyclic amplification of protein misfolding. Nature 411, 810.

SAFAr, J. G. (2012). Molecular pathogenesis of sporadic prion diseases in man. Prion 6 , $108-115$.

Sandberg, M. K., Al-Doujaily, H., Sigurdson, C. J., Glatzel, M., O’Malley, C., Powell, C., Asante, E. A., Linehan, J. M., Brandner, S., Wadsworth, J. D. F. \& Collinge, J. (2010). Chronic wasting disease prions are not transmissible to transgenic mice overexpressing human prion protein. Fournal of General Virology $\mathbf{9 1}$, $2651-2657$.

Seelig, D. M., Mason, G. L., Telling, E. A. \& Hoover, E. A. (2011). Chronic wasting disease prion trafficking via the autonomic nervous system. American fournal of Pathology 179, 1319-1328.

Seidel, B., Thomzig, A., Buschmann, A., Groschup, M. H., Peters, R., Beekes, M. \& Terytze, K. (2007). Scrapie agent (strain 263K) can transmit disease via the oral route after persistence in soil over years. PLoS One 2 , e435.

Selariu, A., Powers, J. G., Nalls, A., Brandhuber, M., Mayfield, A., Fullaway, S., Wyckoff, C. A., Goldmann, W., Zabel, M. M., Wild, M. A., Hoover, E. A. \& Mathiason, C. K. (2015). In utero transmission and tissue distribution of chronic wasting disease-associated prions in free-ranging Rocky Mountain elk. Fournal of General Virology 96, 3444-3455.

Sigurdson, C. J., Barillas-Mury, C., Miller, M. W., Oesch, B., van Keulen, L. J. M., Langeveld, J. P. M. \& Hoover, E. A. (2002). PrPCWD lymphoid cell targets in early and advanced chronic wasting disease of mule deer. Foumal of General Virology 83, 2617-2628.

Sigurdson, C. J., Mathiason, C. K., Perrott, M. R., Eliason, G. A., Spraker, T. R., Glatzel, M., Manco, G., Bartz, J. C., Miller, M. W. \& Hoover, E. A. (2008). Experimental chronic wasting disease (CWD) in the ferret. Fournal of Comparative Pathology 138, 189-196.

Skuldt, L. H., Mathews, N. E. \& Oyer, A. M. (2008). White-tailed deer movements in a chronic wasting disease area in south-central Wisconsin. Journal of Wildlife Management 72, 1156-1160.

Smith, C. B., Booth, C. J. \& Pedersen, J. A. (2011). Fate of prions in soil: a review. Fournal of Environment Quality 40, 449.

Soorae, P. S. (2013). Global Re-Introduction Perspectives: 2013. In Further Case Studies from Around the Globe (ed. P. S. SoorAE). IUCN/ SSC Re-introduction Specialist Group and Abu Dhabi, UAE: Environment Agency-Abu Dhabi, Gland. 
Sorensen, A., van Beest, F. M. \& Brook, R. K. (2014). Impacts of wildlife baiting and supplemental feeding on infectious disease transmission risk: a synthesis of knowledge. Preventive Veterinary Medicine 113, 356-363.

Soto, C. (2012). Transmissible proteins: expanding the prion heresy. Cell 149, 968-977.

Soto, C. \& Satani, N. (2011). The intricate mechanisms of neurodegeneration in prion diseases. Trends in Molecular Medicine 17, 14-24.

Spraker, T. R., Miller, M. W., Williams, E. S., Getzy, D. M., Adrian, W. J., Schoonveld, G. G., Spowart, R. A., O’Rourke, K. I., Miller, J. M. \& Merz, P. A. (1997). Spongiform encephalopathy in free-ranging mule deer (Odocoileus hemionus), white-tailed deer (Odocoileus virginianus) and Rocky Mountain elk (Cervus elaphus nelsoni) in north central Colorado. Jounal of Wildlife Diseases 33, 1-6.

Spraker, T. R., VerCauteren, K. C., Gidlewski, T., Schneider, D. A., Munger, R., Balachandran, A. \& O'Rourke, K. I. (2009). Antemortem detection of PrPGWD in preclinical, ranch-raised Rocky Mountain elk (Cervus elaphus nelsoni) by biopsy of the rectal mucosa. Journal of Veterinary Diagnostic Investigation 21, $15-24$

Storm, D. J., Samuel, M. D., Rolley, R. E., Shelton, P., Keuler, N. S., Richards, B. J. \& VAn Deelen, T. R. (2013). Deer density and disease prevalence influence transmission of chronic wasting disease in white-tailed deer. Ecosphere 4 , 10 .

Tamguney, G., Giles, K., Bouzamondo-Bernstein, E., Bosque, P. J., Miller, M. W., Safar, J., Dearmond, S. J. \& Prusiner, S. B. (2006). Transmission of elk and deer prions to transgenic mice. Fournal of Virology 80, 9104-9114.

Tamgüney, G., Miller, M. W., Wolfe, L. L., Sirochman, T. M., Glidden, D. V., Palmer, G., Lemus, A., Dearmond, S. J. \& Prusiner, S. B. (2009). Asymptomatic deer excrete infectious prions in faeces. Nature 461, 529-532.

Thompson, A. K., Samuel, M. D. \& Van Deelen, T. R. (2008). Alternative feeding strategies and potential disease transmission in Wisconsin white-tailed deer. Fournal of Wildlife Management 72, 416-421.

Thomsen, B. V., Schneider, D. A., O'Rourke, K. I., Gidlewski, T., McLane, J., Allen, R. W., Mcisaac, A. A., Mitchell, G. B., Keane, D. P., Spraker, T. R. \& Balachandran, A. (2012). Diagnostic accuracy of rectal mucosa biopsy testing for chronic wasting disease within white-tailed deer (Odocoileus virginianus) herds in North America: effects of age, sex, polymorphism at PRNP codon 96, and disease progression. Fournal of Veterinary Diagnostic Investigation 24, $878-887$

USDA (2019). Cervids: Chronic Wasting Disease Specifics. Animal and Plant Health Inspection Service. https://www.aphis.usda.gov/aphis/ourfocus/animalhealth/animaldisease-information/!ut/p/z0/fY7NDoIwEISfhiNpMQb1SNSAP'EMvTRrLbIK LXOL6ttLSDSePM18k8lkmGA5EwYGvIJHa6AeuRCxPEXrlC'n0THdbiKeZK vdIVvEnKcztmfif2FcwFvXiYOJZY3XT89yaCskOaHxssazA cKOIG0vZOIVT1 NBAYbqGWlofbVb3JB0kBaoimta6azAVfaDXj5KIXq8YXRU0itVliiItbeRfEGmfipg!!/ Accessed 08.09.2019.

USGS (2019). Distribution of Chronic Wasting Disease in North America (Updated). Expanding Distribution of Chronic Wasting Disease. https://www.usgs.gov/centers/ nwhc/science/expanding-distribution-chronic-wasting-disease?qt-science_center objects=0\#qt-science_center_objects Accessed 13.03.2019.

Vikøren, T., Vage, J., Madslien, K. I., Røed, K. H., Rolandsen, C. M., Tran, L., Hopp, P., Veiberg, V., Heum, M., Moldal, T., das Neves, C. G., Handeland, K., Ytrehus, B., KolbJørnsen, Ø., WisløFF, H., et al. (2019). First detection of chronic wasting disease in a wild red deer (Cerous elaphus) in Europe. Fournal of Wildlife Diseases 55, 2018-2020.

DE Vos, A., Brokx, P. \& Geist, V. (2016). A review of social behavior of the North American cervids during the reproductive period. American Midland Naturalist 77, $390-417$.

Waddell, L., Greig, J., Mascarenhas, M., Otten, A., Corrin, T. \& Hierlihy, K. (2018). Current evidence on the transmissibility of chronic wasting disease prions to humans: a systematic review. Transboundary and Emerging Diseases 65, 37-49.

Wasserberg, G., Osnas, E. E., Rolley, R. E. \& Samuel, M. D. (2009). Host culling as an adaptive management tool for chronic wasting disease in white-tailed deer: a modelling study. Fournal of Applied Ecology 46, 457-466.

Watts, J. C., Giles, K., Patel, S., Oehler, A., Dearmond, S. J. \& Prusiner, S. B. (2014). Evidence that bank vole PrP is a universal acceptor for prions. PLoS Pathogens 10, e1003990.

Wild, M. A., Hobbs, N. T., Graham, M. S. \& Miller, M. W. (2011). The role of predation in disease control: a cmparison of selective and nonselective removal on prion disease dynamics in deer. Fournal of Wildlife Diseases 47, 78-93.

Wilkinson, P. F. \& Shank, C. C. (1976). Rutting-fight mortality among musk oxen on Banks Island, Northwest Territories, Canada. Animal Behaviour 24, 756-758

Williams, E. S. (2005). Review article - chronic wasting disease. Veterinary Pathology $\mathbf{5 4 9}, 530-549$

Williams, A. L., Kreeger, T. J. \& Schumaker, B. A. (2014). Chronic wasting disease model of genetic selection favoring prolonged survival in Rocky Mountain elk (Cervus elaphus). Ecosphere 5, 1-10.

Williams, E. S. \& Young, S. (1980). Chronic wasting disease of captive mule deer: a spongiform encephalopathy. Founal of Wildlife Diseases 16, 89-98.

Williams, E. S. \& Young, S. (1993). Neuropathology of chronic wasting disease of mule deer (Odocoileus hemionus) and elk (Cervus elaphus nelsoni). Veterinary Pathology 30 $36-45$.

Woerman, A. L., Aoyagi, A., Patel, S., Kazmi, S. A., Lobach, I., Grinberg, L. T., McKee, A. C., Seeley, W. W., Olson, S. H. \& Prusiner, S. B. (2016). Tau prions from Alzheimer's disease and chronic traumatic encephalopathy patients propagate in cultured cells. Proceedings of the National Academy of Sciences USA 113, 8187-8196.

Wolfe, L. L., Miller, M. W. \& Williams, E. S. (2004). Feasibility of "test-and-cull" for managing chronic wasting disease in urban mule deer. Wildlife Society Bulletin 32 $500-505$.

YANG, L. H. \& HAN, B. A. (2018). Data-driven predictions and novel hypotheses about zoonotic tick vectors from the genus Ixodes. BMC Ecology 18, 7.

Zabel, M. \& Ortega, A. (2017). The ecology of prions. Microbiology and Molecular Biology Reviews 81, 11-14

(Received 20 May 2019; revised 11 October 2019; accepted 16 October 2019; published online 21 November 2019) 